\title{
Strain rate effect on sooting characteristics in laminar counterflow diffusion flames
}

$$
\text { Yu Wang }{ }^{1,2, *} \text {, Suk Ho Chung }{ }^{2}
$$

1. School of Automotive Engineering, Wuhan University of Technology, Wuhan, P.R. China

2. Clean Combustion Research Center, King Abdullah University of Science and Technology (KAUST), Thuwal, Saudi Arabia 


\title{
Strain rate effect on sooting characteristics in laminar counterflow diffusion flames
}

\author{
Yu Wang ${ }^{1,2, *}$, Suk Ho Chung ${ }^{2}$
}

1. School of Automotive Engineering, Wuhan University of Technology, Wuhan, P.R. China

2. Clean Combustion Research Center, King Abdullah University of Science and Technology (KAUST), Thuwal, Saudi Arabia

\begin{abstract}
The effects of strain rate, oxygen enrichment and fuel type on the sooting characteristics of counterflow diffusion flames were studied. The sooting structures and relative PAH concentrations were measured with laser diagnostics. Detailed soot modeling using recently developed PAH chemistry and surface reaction mechanism was performed and the results were compared with experimental data for ethylene flames, focusing on the effects of strain rates. The results showed that increase in strain rate reduced soot volume fraction, average size and peak number density. Increase in oxygen mole fraction increased soot loading and decreased its sensitivity on strain rate. The soot volume fractions of ethane, propene and propane flames were also measured as a function of global strain rate. The sensitivity of soot volume fraction to strain rate was observed to be fuel dependent at a fixed oxygen mole fraction, with the sensitivity being higher for more sooting fuels. However, when the soot loadings were matched at a reference strain rate for different fuels by adjusting oxygen mole fraction, the dependence of soot loading on strain rate became comparable among the tested fuels. PAH concentrations were shown to decrease with increase in strain rate and the dependence on strain rate is more pronounced for larger PAHs. Soot modeling was performed using detailed PAH growth chemistry with molecular growth up to coronene. A qualitative agreement was obtained between experimental and simulation results, which was then used to explain the experimentally observed strain rate effect on soot growth. However, quantitatively, the simulation result exhibits higher sensitivity to strain rate, especially for large PAHs and soot volume fractions.
\end{abstract}

Keywords: Soot formation, PAH, strain rates, counterflow diffusion flame 


\section{Introduction}

Soot emission from hydrocarbon fuel combustion is a significant environmental [1] and health concern [2] such that related regulations are becoming increasingly more stringent. A major approach of achieving soot reduction is through controlling its formation during the combustion processes. Consequently, a fundamental understanding of the detailed mechanisms leading to soot formation is much required.

The chemistry for the formation of soot and its molecular precursors, i.e. polycyclic aromatic hydrocarbons (PAHs) can be orders of magnitude slower than that for main fuel oxidation [3]. Thus, PAH and soot formations are rate-limiting processes and could be affected appreciably by characteristic flow time scale. Therefore, the effect of flow time on soot and PAH formation is an important research topic.

Counterflow diffusion flame (CDF) is a canonical flame configuration to study flow time effect through variation in strain rate, which can be achieved by changing the nozzle exit velocity. CDF is also a convenient configuration for numerical modeling due to its quasi-one dimensional nature. In addition, it has important applications in laminar flamelet models for turbulent non-premixed flames [4]. With respect to sooting characteristics, the relative location of the flame surface and the stagnation plane differentiates CDF into soot formation (SF) and soot formation oxidation (SFO) flames [5]. Soot zone starts on the fuel side of the flame and are then transported toward the stagnation plane. In a SF flame, the stagnation plane is located on the fuel side of the flame, therefore the soot will be convected away from the high temperature flame zone without being oxidized. On the other hand, in a SFO flame, the stagnation plane is situated at the oxidizer side of the flame and the soot is expected to be convected toward the flame to be oxidized before leaking out.

The effect of strain rate on soot and PAH formation in CDFs has been previously investigated both experimentally [6-12] and numerically $[6,7,11,13]$. The results generally showed that an increase in strain rate reduced both soot volume fraction (SVF) and PAH concentrations. Du et al. [14-16] measured the critical strain rate for soot onset based on the light scattering technique for various gaseous fuels, including 
the effect of dilution. Recognizing the importance of the effect of unsteady strain rate on flamelets [17-19], The response of SVF and PAH concentrations to unsteady strain rates in CDF were studied experimentally $[8,12]$ and computationally $[3,20,21]$. These efforts have contributed significantly to our understanding of the interaction between characteristic flow time and soot/PAH formation. However, systematic data on detailed sooting structure in CDFs with varying strain rate remain limited, especially among different fuels. Notable sooting characteristics study in CDF involving various fuels include [8, 13, 22].

Recently, sooting limit characteristic have been investigated in CDFs and sooting temperature index and sooting sensitivity index have been proposed by varying the nitrogen content in the fuel and oxidizer streams to achieve soot onset [23]. The sooting temperature index (STI) has been defined as either the minimum temperature that could generate soot for SF flames, corresponding to the case with the fuel mole fraction of unity, or the maximum temperature that could generate soot for SFO flames, corresponding to the case with the oxygen mole fraction of unity. These two STIs correlated well with the threshold soot index (TSI) for the tested fuels [23]. The sooting sensitivity index (SSI) was defined as the rate of dependence of STI on strain rate. It has been demonstrated that with varying strain rate in CDFs, STI correlated well with SSI for various fuels [23].

Motivated by this and considering that practical fuels are mixtures of a large number of hydrocarbons, we extend our SSI study to include the effects of strain rate on soot formation for various fuels in actually sooting flames, in addition to the previous sooting limit study. We also note that studies with simultaneous $\mathrm{PAH}$ and soot measurements at various strain rates are limited, while such information could provide a useful database for soot model developments. In this regard, experimental studies were performed on the effect of strain rate on PAH and soot formation in counterflow diffusion flames. Four different fuels $\left(\mathrm{C}_{2} \mathrm{H}_{4}\right.$, $\mathrm{C}_{2} \mathrm{H}_{6}, \mathrm{C}_{3} \mathrm{H}_{6}$ and $\left.\mathrm{C}_{3} \mathrm{H}_{8}\right)$ have been studied. Oxidizer having different oxygen mole fractions $\left(X_{\mathrm{O}}\right)$ was used to examine the effect of oxygen rich environment on soot formation at different strain rates. In addition, numerical modeling of soot formation using recently developed PAH and soot surface growth models were performed for ethylene flames. 
The objectives of this study are to: (1) systematically measure and compare the effects of strain rate on soot and PAH formation in counterflow diffusion flames for various fuels with various level of oxygen enrichment; (2) perform detailed modeling of the sooting structure of ethylene counterflow diffusion flame with varying strain rate and compare with experimental results, for a better understanding of the underlying mechanism regarding the strain rate effect.

It is worthwhile to note here that although some studies of the effects of strain rate on soot formation already existed in literature, we propose to enrich the database with new comprehensive data set as well as detailed soot modeling with the following unique findings/features: (1) We demonstrated that although at a fixed $X_{\mathrm{O}}$, the sensitivity of soot loading to strain rates depends on fuel types, after matching peak soot volume fraction of different fuels at a reference strain rate (through adjusting $X_{\mathrm{O}}$ ), the sensitivity of soot loading to strain rates becomes similar among the tested fuels; (2) We measured PAH fluorescence at various different wavelengths for different size groups as a function of strain rate (and $X_{\mathrm{O}}$ ) and compared the results among a variety of fuels. For different fuels with similar soot loading at a reference strain rate, their PAH level can be significantly different and the sensitivity of PAH to strain rate is also different considerably to that of soot. (3) For a better understanding, we conducted soot modeling for ethylene fuel at various strain rates with detailed gas-phase mechanisms including the formation of large PAHs up to coronene (A7) and compared with experimental data, which has not been done before.

\section{Experiment}

The experimental apparatus consisted of a counterflow burner and mass flow controllers, a laser-induced incandescence (LII) setup for soot volume fraction (SVF) measurement, a laser-induced fluorescence (LIF) setup for PAH measurement and a light extinction/light scattering (LE/LS) setup for SVF, soot number density, and average size measurements. Details of the burner, LII, PAH LIF and LE/LS setups have been reported previously $[24,25]$ and a brief description is given here. The counterflow burner has two opposing divergent-convergent nozzles with an i.d. of $10 \mathrm{~mm}$ and a separation distance of $8 \mathrm{~mm}$. A concentric slit of 
$2 \mathrm{~mm}$ width provided a nitrogen shield. Commercially-pure grade fuel and $\mathrm{O}_{2} / \mathrm{N}_{2}$ mixtures were supplied through the lower and upper nozzles, respectively. The burner assembly was mounted on a two-dimensional translation stage with a movement increment of $100 \mu \mathrm{m}$. The nozzle exit velocities $\left(V_{0}\right)$ tested were 10,15 , 20, 25 and $30 \mathrm{~cm} / \mathrm{s}$, these being controlled by mass flow controllers calibrated with precision positive displacement flow meters. It is worthwhile to point out here that, in the current study, we used global strain rate as represented by $V_{0}$. Although local strain rate obtained from measured velocity profiles $[26,27]$ are a more accurate representation, global values as derived from asymptotic analysis [28] can also provide quantitative information sufficient for this study, considering that in the current study we are more interested in the relative effect of strain rate increase rather than the absolute value of strain rates and that global and local strain rate values were found to be correlated well linearly [7]. Thus, the usage of global strain rate is expected to be acceptable.

The LII technique was used to measure SVFs for ethane, ethylene, propane and propene flames at varying $V_{0}$, while the SVF for the ethylene flame was also measured using the LE/LS technique for cross-checking with the LII result and for modeling test. The flame length, required for the determination of local extinction coefficient in the light extinction technique, was determined from LII images.

In the LII setup, the second harmonic of a pulsed Nd:YAG laser beam (10 ns pulse duration at $10 \mathrm{~Hz}$, $532 \mathrm{~nm}$ ) was shaped to form a vertical sheet beam. The laser fluence was set to be within the saturation regime $[25,29]$. Signal detection was made by an intensified CCD (ICCD) camera with a band pass filter (center wavelength $400 \mathrm{~nm}$, FWHM $40 \mathrm{~nm}[30,31]$ ) to avoid noise from elastic scattering, $\mathrm{C}_{2}$ swan band emission, as well as PAH fluorescence signal, considering that anti-Stokes component of the fluorescence signal is much lower than the stokes component $[32,33]$. The ICCD gate was opened $30 \mathrm{~ns}$ after the laser and the gate duration was set at $80 \mathrm{~ns}$. This $30 \mathrm{~ns}$ delay also helped to reduce PAH interference since the lifetime of fluorescence is much shorter than the incandescence signal originated from black body radiation. The short gate width (80 ns) also enhanced the inhibition of the background incandescence signals from 
soot at flame temperature, which contributed to the background signals and was thus subtracted during postprocessing.

For the PAH LIF measurements, a laser sheet was formed from a dye laser at around $283 \mathrm{~nm}$ with energy of about $1 \mathrm{~mJ} /$ pulse. It has been confirmed that there was no LII signal if such laser energy was used in the LII experiments such that LII interference with PAH fluorescence signal was avoided. Narrow band-pass filters at $\lambda=330$ (FWHM $10 \mathrm{~nm}$ ), 400, 450, $500 \mathrm{~nm}$ (FWHM $40 \mathrm{~nm}$ ) were used to detect the fluorescence signals through the ICCD camera. Note previous studies have shown that LIF signals detected at longer wavelength represents larger aromatic species, although pinpoint of a specific PAH was not possible [3436]. The ICCD gate was opened for $50 \mathrm{~ns}$ after the laser without delay. Images taken by the ICCD camera were averaged over 600 laser shots, after which the background image (with flame but without the laser shot) was subtracted. Signal trapping in both the LII and LIF signals were not observed, most probably because the sooting zone of the CDF was very thin $(\sim 1 \mathrm{~mm})$ and the signal collection solid angle was relatively large. The errors (estimated from standard deviation) of LII and LIF signal intensities were around $4.5 \%$, as derived from the data from 600 laser shots.

For the ethylene CDFs, SVF, average particle size $\left(D_{63}\right)$ and number density were measured by LE/LS techniques using an Ar-ion laser operated at $514.5 \mathrm{~nm}$ and $0.5 \mathrm{~W}$. The schematic of a similar setup can be found in our previous paper [23]. The incident beam passed a mechanical chopper, a half-wave plate, an iris and was then focused by a plano-convex lens $(\mathrm{f}=1 \mathrm{~m})$ to a spot at the center axis of the burner. The chopper modulated the beam with a frequency of $1015 \mathrm{~Hz}$ and was used in conjunction with digital lock-in amplifiers, which filtered, amplified and digitized both the extinction and scattering signals with enhanced signal-to-noise ratio. A half-wave plate was used to achieve vertical polarization of the beam. Care has been taken to make sure the beam is parallel to the nozzle exit planes (and thus the flame). After passing the flame, the transmitted beam was re-focused by a bi-convex ( $\mathrm{f}=125 \mathrm{~mm}$ ) lens to a detector assembly, which is composed of a ND filter (O.D. =2), a laser-line narrow band filter, an integrating sphere and an amplified Si photodiode for the extinction measurement. The bi-convex lens and the integrating sphere were used to 
minimize beam steering caused by the steep density gradient of the flame. The scattering setup was arranged at $90^{\circ}$ to the incident beam and included an iris, a bi-convex lens ( $\left.\mathrm{f}=1 \mathrm{~mm}\right)$, a polarizer, a ND filter (O.D. =1) and a narrow band pass filter $(\mathrm{FWHM}=1 \mathrm{~nm})$ placed in series in front of a photomultiplier tube. The scattering signals of propane and nitrogen at room temperature were measured and their ratio was validated with theoretical data to make sure the scattering signal was not contaminated by a stray beam.

The detailed data reduction of the LE/LS signals followed ref. [37]. A constant soot refractive index of (1.57-0.56i) was used independent of the measuring region. Note that although soot refraction index may vary depending on their sizes [38], reliable data to take this into account in a very narrow sooting zone (FWHM $\sim 1 \mathrm{~mm}$ ) was not available. We also noted recent studies have proposed the usage of light source with wavelength longer than $800 \mathrm{~nm}$ for LE measurement to avoid interference from PAH absorption [3943]. These studies are mostly done for flat premixed flames (ref. [43] is for coflow flames), which may exhibit difference compared to CDF since soot in these two types of flames are formed in quite different environments. In this regard, we are planning to investigate the effect of light wavelength in LE measurements for CDFs. In addition, the absolute SVF will be affected by PAH absorption, however, the relative strain rate effect (as our focus) will be less affected. From a comparable results from LE and LII measurements (shown later), these assumptions seem to be acceptable.

\section{Numerical modeling}

Numerical modeling was performed for PAH formation for various fuels with varying strain rate. In our previous studies [44, 45], the gas-phase mechanism of KAUST PAH Mech 2 (KM2) [44] was developed by adopting the USC II mechanism [46] as a base mechanism for small chemical species up to benzene. Reactions leading to larger PAHs up to seven-ring aromatics (coronene) were then added, which includes odd-carbon pathways involving species such as propargyl, benzyl, and indenyl. The resulting KM2 mechanism has 202 species and 1351 reactions. 
Numerical simulation of soot formation has also been performed for ethylene fuel with synthetic air (25\% $\mathrm{O}_{2} / 27 \% \mathrm{~N}_{2}$ ). A recently proposed soot surface growth model was coupled to the KM2 and details can be found in $[44,45]$. Only a brief description is provided here. The soot model includes soot nucleation reactions from large PAH molecules. Eight PAH molecules, namely, pyrene, 1-ethynyl pyrene, 2-ethynyl pyrene 4-ethynyl pyrene, benzo(a)pyrene, benzo(e)pyrene, benzo(ghi)perylene and coronene were allowed to form dimers (soot nucleus) from a total of $36\left({ }^{8} \mathrm{C}_{2}+8\right)$ nucleation reactions. The collision efficiencies depended on the size of nucleating PAHs, whose details together with a corrector constant can be found in [45]. We only allowed those PAHs that are larger than pyrene to form dimers mainly because the probability of smaller PAHs to form dimers are rather low. This is due to the following facts: (1) Smaller PAHs have lower boiling point and thus are more likely to vaporize instead of getting condensed in flame conditions; (2) Smaller PAH molecules have less degree of freedom and the excess collision energy between two such molecules would more likely to result in the bounce-back instead of sticking, in which case the collision energy needs to be dissipated in the internal motion of the dimer. The lower limit of pyrene is based on many previous studies [47] and it is of interests to further investigate this choice in more detail in future studies.

Soot surface growth was described through the hydrogen-abstraction- $\mathrm{C}_{2} \mathrm{H}_{2}$-addition (HACA) reactions. In contrast to the formalism of Appel et al. [47], where only $\mathrm{H}$ and $\mathrm{OH}$ radical contributed to the $\mathrm{H}$ abstraction, the present surface growth reactions adopted the modified-HACA mechanism [45, 48], including the $\mathrm{H}$ abstraction through $\mathrm{CH}_{3}, \mathrm{C}_{3} \mathrm{H}_{3}$ and $\mathrm{C}_{2} \mathrm{H}$ radicals in addition to $\mathrm{H}$ radical. Those reactions are shown as follows while the reaction rates can be found in the soot surface mechanism provided in the supplementary material of a previous paper [45].

$$
\begin{gathered}
C_{\text {soot }}-H+\mathrm{CH}_{3} \leftrightarrow C_{\text {soot }} \cdot+\mathrm{CH}_{4} \\
C_{\text {soot }}-H+C_{3} H_{3} \leftrightarrow C_{\text {soot }} \cdot+C_{3} H_{4} \\
C_{\text {soot }}-H+C_{2} H \leftrightarrow C_{\text {soot }} \cdot+C_{2} H_{2} .
\end{gathered}
$$


The eight soot nucleating PAH molecules were also allowed to condense on the surface of soot particles [45]. Since condensation is mainly a physical process, no site species were required as opposed to the HACA surface growth reactions. Particle coagulation was also considered with a collision efficiency of 2.2 considering the van der Waals enhancement factor of 2.2 [49]. As will be shown later, the counterflow diffusion flames studied here are located on the oxidizer side and thus correspond to the soot formation (SF) flame [5], where soot particles are formed on the fuel side and then are convected away from the high temperature flame zone toward the stagnation plane. As a result, soot oxidation was absent.

The particle dynamics were treated using the method of moments and the details can be found in [50]. Briefly, the size distribution function was represented by moments and the 3 integer moments were directly solved from their transport equations. Fractional moments, which are needed to describe, e.g. the particle surface area are obtained from logarithmic interpolation of the integer moments [51]. The transport equations were numerically solved with the opposed-flow module in the Chemkin Pro package [52]. The gas phase species equations and particle phase moment transport equations were solved in a segregated manner and were then iterated to achieve convergence, such that the gas phase species and particle formation are coupled with each other.

\section{Results and discussion}

\subsection{Influence of oxygen mole fraction $\left(X_{0}\right)$}

We first present the experimental data regarding the effect of oxygen enrichment on soot formation of ethylene CDFs at various strain rates. In a soot formation $(\mathrm{SF}) \mathrm{CDF}$, the increase in $\mathrm{O}_{2}$ mole fraction $\left(X_{\mathrm{O}}\right)$ in the oxidizer stream can increase soot loading, mainly through its effect on flame temperature. As $X_{\mathrm{O}}$ increases, the flame temperature increases by the decrease in the level of dilution. Consequently, fuel pyrolysis [6], PAH and soot surface growth through the HACA mechanism will be enhanced. Considering the recent research interests in oxy-fuel/oxygen-enriched combustion, it is of practical relevance to quantify the effect of oxygen enrichment on soot formation, especially with varying strain rates. 
In the study of the effect of $X_{\mathrm{O}}$ and fuel type (next section) on soot formation with varying strain rate, the LII signal represents SVF, since the signal is reasonably proportional to SVF [53]. We also performed LE measurement to obtain SVF data for several ethylene flames at varying strain rates to confirm the LII signal representing SVFs. The usage of these two techniques allowed us to cross-validate the data. As will be shown later, the agreement between these two techniques were indeed satisfactory. It is worthwhile to note here that since the LE techniques provide quantitative values of SVF, by comparing the experimental peak SVF values (will be shown in Fig. 9a) and the corresponding LII intensities we can derive the conversion factor between LII intensities and SVF to be 5330 LII signal counts per ppm. As such, we were able to convert LII signal intensities to quantitative values of SVF, as done in Figs. 1-3.

The peak SVF of the $\mathrm{C}_{2} \mathrm{H}_{4} \mathrm{CDFs}$ as a function of $V_{0}$ at $X_{\mathrm{O}}=0.25,0.30,0.35$ and 0.40 for the fuel mole fraction $X_{\mathrm{F}}=1$ are shown in Fig. 1 in terms of absolute value (a) and the data normalized at $V_{0}=10 \mathrm{~cm} / \mathrm{s}$ (b). At a specified $V_{0}, \mathrm{SVF}$ increases with increasing $X_{\mathrm{O}}$. This is consistent with previous findings $[6,54]$ and can be understood from the temperature effect. As mentioned previously, SF flames with higher $X_{\mathrm{O}}$ have a higher temperature in the fuel pyrolysis zone. This increase in temperature, together with higher intermediate species concentration due to less $\mathrm{N}_{2}$ dilution, would enhance the reactions leading to PAHs and soot formation.

In all of the $X_{\mathrm{O}}$ cases, SVF decreases as $V_{0}$ increases. Increase in $V_{0}$ and thus strain rate reduces the residence time for soot formation. As soot growth is a relatively slow process and thus kinetically controlled, such decrease in residence time would naturally decrease soot formation. In addition, increase in strain rate would reduce the flame temperature due to both finite rate chemistry effect [55] and preferential diffusion [56], which could also reduce the rate of soot formation. Note also that in Fig. 1a reasonably linear relation was observed between peak SVF and $V_{0}$, when plotted in log scale. The effect of $V_{0}$ on sooting structure of CDFs will be analyzed and explained in detail later.

The relative sensitivity of peak SVF on $V_{0}$ (slope with $V_{0}$ in the normalized data) becomes amplified as $X_{\mathrm{O}}$ decreases (flame with lower soot loading has larger slope). This implies that less sooting flames have a 
higher sensitivity to strain rate. This is in qualitative agreement with our recent work on sooting limits for various fuels [23]. This point is further investigated in the following.

\subsection{Effect of fuel type}

Fuel type is one of the dominant factors controlling soot formation $[57,58]$. In this regard, SF flames of $\mathrm{C}_{2} \mathrm{H}_{4}, \mathrm{C}_{2} \mathrm{H}_{6}, \mathrm{C}_{3} \mathrm{H}_{6}$ and $\mathrm{C}_{3} \mathrm{H}_{8}$ fuels were studied at various $V_{0}$ and $X_{\mathrm{O}}$. Figure 2 shows the variation of peak SVF with $V_{0}$ for the fuels mentioned above at $X_{\mathrm{F}}=1$ and $X_{\mathrm{O}}=0.35$ both in terms of absolute (a) and normalized (b) data. At a fixed $V_{0}$, the propene $\left(\mathrm{C}_{3} \mathrm{H}_{6}\right)$ flame produces the highest soot level and the ethane $\left(\mathrm{C}_{2} \mathrm{H}_{6}\right)$ flame the lowest, with the order of $\mathrm{C}_{3} \mathrm{H}_{6}>\mathrm{C}_{2} \mathrm{H}_{4}>\mathrm{C}_{3} \mathrm{H}_{8}>\mathrm{C}_{2} \mathrm{H}_{6}$. This result agrees well with the previous sooting tendency data obtained from either co-flow [59, 60] or counterflow diffusion [23] flames. For example, Calcote and Manos [59] reported the threshold soot index (TSI) of 2.6, 1.3, 0.6 and 0.0 for $\mathrm{C}_{3} \mathrm{H}_{6}, \mathrm{C}_{2} \mathrm{H}_{4}, \mathrm{C}_{3} \mathrm{H}_{8}$ and $\mathrm{C}_{2} \mathrm{H}_{6}$, respectively, where higher TSI implies higher sooting propensity.

As $V_{0}$ increases, the peak SVF decreases for all fuel types, while the sensitivity of the decreasing slope with $V_{0}$ depends on the fuel type. For instance, as $V_{0}$ increases from 10 to $30 \mathrm{~cm} / \mathrm{s}$, the peak SVF dropped by over $90 \%$ for the flame of $\mathrm{C}_{2} \mathrm{H}_{6}$, the least sooting fuel, whereas there was only a $20 \%$ reduction for that of $\mathrm{C}_{3} \mathrm{H}_{6}$, the most sooting fuel. This fuel type dependence is qualitatively consistent with a numerical simulation by Huijnen et al. [13], who reported that the computed peak SVF of a benzene CDF dropped by $70 \%$ as strain rate increased from 10 to $40 \mathrm{~s}^{-1}$, while that of a $\mathrm{C}_{2} \mathrm{H}_{4}$ flame decreased by more than $98 \%$. Note that the benzene flame was much more sooting than the $\mathrm{C}_{2} \mathrm{H}_{4}$ flame at a specified reference strain rate. Also, this trend of a more sooting fuel having less sensitivity to strain rate is consistent with our recently proposed sooting sensitivity index (SSI) results [23].

Note, as previously mentioned, that for the $\mathrm{C}_{2} \mathrm{H}_{4} \mathrm{CDF}, \mathrm{SVF}$ is less sensitive to the strain rate in cases of higher $X_{\mathrm{O}}$ (more sooting) flames. The data shown in Fig. 2 also exhibits that SVF is less sensitive to strain for fuels with a higher sooting tendency. A question remains as to whether this sensitivity is solely due to different fuel molecular structures or simply because of the different soot loading among these fuels at a 
reference strain rate. To investigate this question, we have adjusted soot loading of different fuels to have comparable peak SVF at the reference $V_{0}(10 \mathrm{~cm} / \mathrm{s})$ by changing the oxygen mole fraction of flames of respective fuels (higher $X_{\mathrm{O}}$ for lower sooting tendency fuel).

The result is shown in Fig. 3 for relatively high $\left(\mathrm{C}_{2} \mathrm{H}_{4}, \mathrm{C}_{3} \mathrm{H}_{8}\right.$, and $\mathrm{C}_{3} \mathrm{H}_{6}$, solid lines) and low $\left(\mathrm{C}_{3} \mathrm{H}_{8}\right.$ and $\mathrm{C}_{2} \mathrm{H}_{6}$, dashed lines) soot loading cases, depending on the sooting tendency of the fuels. The result clearly shows that the dependence of peak SVF on $V_{0}$ becomes independent of fuel as long as the soot loading is similar for a given strain rate. This implies that for the fuels tested here, the flames of similar soot loading would have a comparable sensitivity to strain rate, irrespective of fuel type.

To achieve a better description of this trend, we calculated the average slope of SVF (as represented by the normalized LII signals $\mathrm{LII}_{\text {norm}}$ ) against $V_{0}$ for a particular combination of fuel type and $X_{\mathrm{O}}$ and correlated the results with the peak SVF of the flame at $V_{0}=10 \mathrm{~cm} / \mathrm{s}$ with corresponding fuel type and $X_{\mathrm{O}}$. Normalized data was used to study the relative effect compared to a reference strain rate. The results for various combinations of fuel type and $X_{\mathrm{O}}$ are shown in Fig. 4. Let us take the black square with 0.30 attached to it (let us call it point A) for $\mathrm{C}_{2} \mathrm{H}_{4}$ flame at $X_{\mathrm{O}}=0.30$ as an example to describe how Fig. 4 was obtained. The $X$ coordinate of point $\mathrm{A}$ is the maximum LII intensity of the $\mathrm{C}_{2} \mathrm{H}_{4}$ flame with $X_{\mathrm{O}}=0.30$ and $V_{0}=10 \mathrm{~cm} / \mathrm{s}$, which can be obtained from the $Y$-axis value of the left-most circle (red) in Fig. 1(a). The $Y$ coordinate of point $\mathrm{A}$ is the slope of the line of circles (red) in Fig. 1(a), after being linearly fitted. Similar procedures were done for all other 9 points (fuel type and $X_{\mathrm{O}}$ combinations) shown to obtain Fig. 4 . The result clearly shows a reasonable negative correlation between the sensitivity of SVF to $V_{0}$ and the SVF at the reference $V_{0}$ of $10 \mathrm{~cm} / \mathrm{s}$. Fuel type and $X_{\mathrm{O}}$ are not seen to contribute much in this correlation, confirming that the soot loading in the flame itself is the primary factor affecting its sensitivity to $V_{0}$. Note, however, that only several gaseous aliphatic fuels have been tested at present. Additional work covering more variation in fuel structures, such as aromatics and oxygenated fuels, is required in order to draw a more general conclusion. In the tested cases with different fuels, flame temperature also varies since oxygen concentration is adjusted, leading to various influencing factors on PAH growth, inception rate, and soot growth. Therefore, more 
detailed measurements of flame structures as a function of strain rates, in terms of temperature and intermediate hydrocarbons relevant to soot formations such as acetylene, propargyl, allyl, cyclopentadienyl, benzyl, and indyl radicals need to be performed and analyzed, preferably by molecular beam mass spectrometry $[61,62]$. Corresponding kinetic mechanisms and model validation are also required for other fuels to further understand the underlying mechanisms. These will be the focus of our future study on the current topic.

Nonetheless, a tentative explanation can be given as follows. At the reference strain rate the time available for soot growth are reasonably similar for all flames. For the peak soot volume fractions to be matched by adjusting the oxygen concentrations for different fuels, it is expected that the average soot growth rates are similar among the fuels tested. In addition, since the tested flames are all of SF type, the soot growths all follow similar phenomenological patterns, i.e., soot is formed at the fuel side of the flame and then are transported toward the stagnation plane, during which process surface reactions continue to increase the soot mass without oxidation. Therefore, the soot growth rate profiles are expected to be similar. In such a case, the decrease in residence time by strain rate would result in similar amount of decrease in soot loadings for all the cases. It is also interesting to note that our recent work on sooting limits in CDFs [23] demonstrated an excellent correlation between the proposed sooting propensity metric of the sooting temperature index (STI, defined as the flame temperature at sooting limit by varying $X_{\mathrm{O}}$ for $X_{\mathrm{F}}=1$ ) and the sooting sensitivity index (SSI, sooting limit temperature dependence on strain rate) [23]. However, details of the effect of temperature (by varying $X_{\mathrm{O}}$ for different fuels) and chemical pathways leading to PAH and soot formation for different fuels on the above behavior should be a future study.

\subsection{Relative PAH concentrations}

Advanced soot models treat various PAHs as precursors for soot inception from which nascent soot particles are formed. Increase in strain rate is expected to decrease PAH concentrations, which can be one 
of the reasons for the reduced soot volume fraction. This section will present results on the effect of strain rate on PAH formation.

The effect of $X_{\mathrm{O}}$ and $V_{0}$ on peak PAH concentration (normalized at $V_{0}=10 \mathrm{~cm} / \mathrm{s}$ ) from PAH LIF signal intensity is shown in Fig. 5 for propane CDFs with the detection wavelengths at $\lambda=330$ and $500 \mathrm{~nm}$. The signals decrease with the increase in $V_{0}$ in general, while the slope of the decrease is higher for lower $X_{\mathrm{O}}$ cases. This trend is consistent with that in the LII signals in Fig. 1 (less sooting flames have higher sensitivity to strain). As the detection wavelength increases, the PAH LIF signal becomes more sensitive to $V_{0}$ and the data at $\lambda=400$ and $450 \mathrm{~nm}$ (not shown) confirms the trend. Note again that LIF signals detected at longer wavelengths represent larger aromatic species [34-36].

PAH LIF signals for different fuels at the conditions corresponding to those shown in Fig. 3 (solid lines) are shown in Fig. 6. For these conditions, at a fixed $V_{0}$, SVFs are comparable among different fuels. The peak PAH signals are highest for the propene fuel and lowest for ethylene. Note that the flame temperature of propene is lowest because of its low $X_{\mathrm{O}}=0.19$. Since HACA growth rate depends on flame temperature, for the low temperature propene flame to have similar soot loading, it requires higher PAH concentrations for soot nucleation and thus having larger soot surface area available for mass growth. In the $\mathrm{C}_{3} \mathrm{H}_{8}$ flame, the higher PAH concentration could be counter-acted by lower $\mathrm{C}_{2} \mathrm{H}_{2}$ production [54] resulting in the similar soot loading. Regarding the sensitivity to strain rate (b), again it is seen that PAH signal at larger $\lambda$ are more sensitive to strain. In addition, the ethylene flames are more resistant to strain in terms of PAH formation, compared to the propene and propane flames.

As mentioned previously, an accurate prediction of PAH concentration is the first step in the simulation of soot formation. In this regards, we have tested the performance of the PAH growth mechanism KM2 [44] together with a soot model [45] in terms of the effect of strain rate on PAH formation.

The computed normalized concentrations of PAHs of different sizes (A1 benzene, A2 naphthalene, A3 phenanthrene, A4 pyrene and A7 coronene) are shown in Fig. 7 for the ethylene CDFs, corresponding to 
the flame conditions for which we will analyze the sooting structure in detail in the next section. The simulations were conducted using the opposed flow module of Chemkin Pro package [52]. A newly developed soot model [45] was also included. The numerical results showed that the concentrations of larger PAHs decrease faster with $V_{0}$. The experimentally obtained normalized PAH LIF signals detected at $\lambda=$ 330, 400, 450 and $500 \mathrm{~nm}$ are also shown (dotted lines) in comparison, these exhibiting higher sensitivity to strain as $\lambda$ increases and thus are consistent with the trends shown in the numerical data.

The LIF signals detected at $330 \mathrm{~nm}$ has been shown to correlate reasonably with two to three ring aromatics (A2 and A3) previously [36] and as the detection wavelength increases, it is related to species having higher number of aromatic rings [34]. Our recent PAH simulation of the synergistic effect in PAH production [44], achieved by varying ethylene/propane mixing ratio, also substantiated that PAH data at $330 \mathrm{~nm}$ is in good qualitative agreement with computed A2 and A3 concentration behavior. A comparison between the present experimental and computational results indicates that the numerical prediction agrees qualitatively with the experiment. However, it should be emphasized that the LIF signals cannot pinpoint specific PAH molecules because of broad absorption and emission characteristics of PAH molecules. Rather, the LIF signals only represent a class of PAHs that increase in size with increase in the detection wavelength. In the simulation results, A4 is slightly less sensitive to $V_{0}$ as compared with A3, which might be caused by the fact in the simulation A4 was allowed to nucleate soot while A3 was not. Since the soot level is higher at lower $V_{0}$, which implies higher PAH (those allowed to nucleate soot) consumption to form soot, the inclusion of soot model in the simulation is expected to reduce the sensitivity of the computed PAH (those allowed to nucleate soot) concentrations on $V_{0}$. As a result, the sensitivity of A4 was directly affected by soot model while A3 was not. We note in reality there might not be such a clear cut in PAH size in terms of their ability to nucleate soot.

From a modelling perspective, the most important mass growth pathway for soot is through HACA reaction in which the $\mathrm{C}_{2} \mathrm{H}_{2}$ plays an important role and the strain rate could influence peak SFV through residence time. While PAH can be formed via many different chemical pathways and thus could be 
appreciably different in flames of different fuels. Furthermore, besides convection transport, diffusion can also be important for PAH molecules, which makes the profiles of PAH formation rates rather complex. In addition, the peak PAH is already quite different at the reference strain rate. The above facts combined may help explain why strain rate sensitivity of peak PAH LIF is still dependent on fuel, even when flames of different fuels have the same soot loading at a reference strain rate, as shown in Fig. 6. In the modeling aspect, we demonstrated (will be shown in the next section) that the SVF sensitivity to strain rate is currently over predicted for ethylene fuel, which is one of the limiting factors in explaining the observed PAH and SVF behavior for the fuels tested based on the modeling.

\subsection{Sooting structure of ethylene CDFs with strain rates}

To understand the underlying mechanism of the experimentally observed strain rate effects on soot formation, it is necessary to investigate the detailed sooting structures of CDFs. In this regard, we have performed soot modeling for ethylene CDFs at $X_{\mathrm{O}}=0.25$ with $V_{0}$ varying from $15 \mathrm{~cm} / \mathrm{s}$ to $30 \mathrm{~cm} / \mathrm{s}$. The modeling method has been explained in Section 3. The soot precursor (PAH) data has been discussed in the last section and here we are focusing on the sooting structure. Corresponding experimental data on SVF, average particle size and soot number density were obtained from LE/LS technique.

Before going into the discussion on soot formation, we first present the flame structures of the studied ethylene CDFs, where the fuel streams were pure $\mathrm{C}_{2} \mathrm{H}_{4}\left(X_{\mathrm{F}}=1\right)$ and the oxidizer was $25 \% \mathrm{O}_{2} / 75 \% \mathrm{~N}_{2}\left(X_{\mathrm{O}}\right.$ $=0.25)$. The computed profiles of temperature, axial velocity, $\mathrm{C}_{2} \mathrm{H}_{2}$ and pyrene mole fractions as a function of distance from fuel nozzle $(Z)$ are shown in Fig. 8. The computed gas-phase velocity was corrected for the thermophoretic effect to represent the soot particle velocity $V_{\mathrm{s}}[63]$, using the thermophoretic velocity as [30]:

$$
\vec{v}_{t}=-\frac{3 v}{4\left(1+\frac{\pi \alpha}{8}\right)} \cdot \frac{\nabla T}{T}
$$


where $v$ is the gas-phase viscosity and $\alpha$ is the momentum accommodation coefficient which is set as unity [31].

As $V_{0}$ increases, both the peak temperature and thickness of the high temperature zone decrease (a), an indication of increasing strain weakening the flame, in accordance with a previous study [11]. The position of peak temperature shifts slightly toward the fuel side with $V_{0}$. The axial particle velocity (b) shows: (1) on the fuel side, the velocity continues to decelerate toward the stagnation plane and (2) on the oxidizer side, the velocity decelerates, accelerates due to thermal expansion, and decelerates again toward the stagnation plane. The particle stagnation planes can be identified in a region of $Z=2.6-2.9 \mathrm{~mm}$.

As will be shown later, sooting zones are located between the particle stagnation plane and the flame such that soot particles incepted on the fuel side of flame will be convected toward the stagnation plane, where they eventually leak out. This type of sooting behavior has been classified previously as the soot formation (SF) flame [5].

The mole fraction profiles of $\mathrm{C}_{2} \mathrm{H}_{2}$ and pyrene are shown in Fig. 8c, these being relevant for soot formation. $\mathrm{C}_{2} \mathrm{H}_{2}$ is an important species for the HACA reactions for $\mathrm{PAH}$ and soot growth, and pyrene (A4) is widely adopted as a precursor for soot inception $[64,65]$. The thickness of the $\mathrm{C}_{2} \mathrm{H}_{2}$ zone decreases appreciably, especially on the fuel side, while the peak value decreases only slightly as $V_{0}$ increases. Both the pyrene peak concentration and the zone thickness decrease noticeably.

The measured (by LE/LS technique) and computed SVF profiles are shown in Fig. 9a as symbols and lines, respectively, where the flame location and the particle stagnation plane were marked. We would like to point out the PAH nucleation correction constant used for the simulation has the same value as in our previous study [45], which was obtained by experimental validation. For the comparison with the experimental data, the computed profiles were averaged over a distance of $250 \mu \mathrm{m}$, taking into account the effect of finite beam diameter during the line-of-sight extinction measurements.

The overall soot profiles can be seen to be well predicted. The sooting zones were located on the oxidizer side of the particle stagnation plane. The SVF profiles are highly skewed toward the particle stagnation 
plane. As mentioned above, these counterflow flames are of the SF type and soot particles are formed on the fuel side from the flame and then grow continuously as they are convected toward the particle stagnation plane, and eventually leak through it, resulting in a sharp decrease in SVF across the stagnation plane.

The normalized peak SVF data from both experiments and simulation are shown in Fig. 9b as a function of $V_{0}$. Note here that the normalized experimental data for SVF derived from both LII and LE are shown. A satisfactory agreement was obtained between these two sets of data, confirming the validity of both measurement techniques. Increase in $V_{0}$ (strain rate) reduces the soot loadings appreciably. The experimental data showed that the peak soot volume fraction decreases by $41.5 \%$ from 0.65 to 0.38 ppm as $V_{0}$ increases from 20 to $30 \mathrm{~cm} / \mathrm{s}$. We note that although this qualitative decreasing trend was captured by the soot model, the quantitative value of the sensitivity of soot loadings to strain rates was over-predicted. The numerical results showed a reduction of $76.5 \%$ (from 0.64 to $0.15 \mathrm{ppm}$ ) in peak SVF as $V_{0}$ increased from 20 to $30 \mathrm{~cm} / \mathrm{s}$.

This over-prediction could be partially explained as follows. As shown in the last section, the sensitivity of mole fractions of larger PAHs (such as pyrene and coronene) to strain rates were over-predicted by the gas-phase chemistry, as compared to experimental PAH LIF data. As soot particles are incepted from large PAHs, this over-prediction on PAH sensitivity to strain rates were expected to translate to soot predictions. In this regard, the gas-phase mechanism may need to be further refined and optimized against accurate quantitative measurement of PAH species at varying strain rates, preferably through molecular mass spectrometry such as in [66-68]. This will be our future study.

Both the experimental and numerical data showed that the sooting zone thickness decreases with increasing strain rates, consistent with literature results [8]. As shown in Fig. 8c, the narrowing of the $\mathrm{C}_{2} \mathrm{H}_{2}$ zone (important for soot surface growth through the HACA mechanism) and that of pyrene (important for soot nucleation) also support this observation.

The comparison of the measured and the simulated profiles of soot particle size $D_{63}$ with varying strain rates are shown in Fig. 10 with $D_{63}$ from the following definition: 


$$
D_{63}=\left[\frac{\sum_{j=0}^{\infty} N(j) \cdot D(j)^{6}}{\sum_{j=0}^{\infty} N(j) \cdot D(j)^{3}}\right]^{1 / 3}
$$

where $N(j)$ and $D(j)$ are the number concentration and diameter, respectively, of the particle of size class $j$. The measured $D_{63}$ was obtained from the LE/LS data through the procedure described in [37] while the computed one was derived from the following equation:

$$
D_{63}=\left[\frac{\sum_{j=0}^{\infty} N(j) \cdot D(j)^{6}}{\sum_{j=0}^{\infty} N(j) \cdot D(j)^{3}}\right]^{1 / 3}=\left[\frac{\sum_{j=0}^{\infty} N(j) \cdot\left(d_{0} \cdot j^{\frac{1}{3}}\right)^{6}}{\sum_{j=0}^{\infty} N(j) \cdot\left(d_{0} \cdot j^{\frac{1}{3}}\right)^{3}}\right]^{1 / 3}=d_{0}\left(\frac{M_{2}}{M_{1}}\right)^{1 / 3}
$$

where $M_{1}$ and $M_{2}$ are the computed moments of the particle size distribution functions.

Starting from the oxidizer side (large $Z$ ) from the stagnation plane, the particle size continues to increase as the particles are convected toward the stagnation plane. The peak value of $D_{63}$ appears near the stagnation plane, which decreases with the strain rate. Experimentally, $D_{63}$ decreased from about $58 \mathrm{~nm}$ at $V_{0}=15$ $\mathrm{cm} / \mathrm{s}$ to about $40 \mathrm{~nm}$ at $30 \mathrm{~cm} / \mathrm{s}$. Again we notice the over-prediction of the sensitivity of $D_{63}$ to strain rates, similar with the case for SVF as discussed earlier. The size of particles depends on both surface growth and particle-particle coagulation, which are influenced by the reduction of residence time due to the increase in the strain rate.

The soot number density (primary particle), as shown in Fig. 11, decreases as the incepted particles travel from near the flame to the particle stagnation plane, due to particle coagulation. The peak soot number density decreases with increasing $V_{0}$, which can be attributed to decreases in PAH mole fractions (e.g. pyrene in Fig. 8c) in the soot inception zone. Since PAHs are molecular precursors for soot inception, a higher PAH concentration would result in a higher nucleation rate and thus higher soot number density in the inception zone. Note in Fig. 11, instead of using the zeroth moment directly, the numerical soot number density $\boldsymbol{N}_{\Sigma}$ was derived from the computed $D_{63}$ and SVF through the following expression:

$$
N_{\Sigma}=\left(\frac{6 f_{v} R}{\pi D_{63}^{3}}\right)
$$

where $R$ is defined as $\left(D_{63} / D_{30}\right)^{3}$ and a value of 2.1 was used, assuming a self-preserving size distribution [69]. This same expression was also used to derive the experimental number density from measured SVF 
and $D_{63}$, therefore, this is performed for the simulated data for a consistent comparison with experiments. In LE/LS measurements, SVF and $D_{63}$ are direct measurement quantities while soot number density is a derived value with an assumed and constant value of $R$. Note, however, in reality $R$ may be different at different flame locations and as a result the comparisons here may have inherent discrepancy. A better option would be to use the methodology of time-resolved LII and a soot size-dependent heat dissipation model to resolve size distribution functions. This is, however, beyond the scope of the current study although it will be actively pursued by us for future studies.

Increase in $V_{0}$ could slow down soot formation due to several reasons. First, as discussed before and shown in Fig. 8c, PAH concentrations were significantly reduced as $V_{0}$ increased. Since soot particles are incepted from large PAHs, the decrease in PAH concentration would result in a decrease in soot nucleation rates. To confirm this, Fig. 12a shows the computed soot nucleation rates (soot mass growth rate by all 36 nucleation reactions) at several strain rates. The soot nucleation rate peaks near $Z=3.5 \mathrm{~mm}$, where the PAH concentration peaks, e.g., pyrene in Fig. 8c. This indicates a close relationship between PAH concentrations and soot nucleation rates. As $V_{0}$ increases from 15 to $30 \mathrm{~cm} / \mathrm{s}$, the peak soot nucleation rate decreases by more than $50 \%$.

Second, low nucleation rates in flames with high $V_{0}$ lead to lower soot number densities in the soot inception regions. As a result, surface area of particles available for soot growth will also decreases as $V_{0}$ increases. This is confirmed in Fig. 12b, where the simulated soot surface area per unit volume is presented. Naturally, the soot surface growth rate (per unit volume) also decreases as $V_{0}$ increased since less active surface areas are available. In Fig. 12c, the HACA surface growth rates per unit volume with the unit of $\mathrm{g} /\left(\mathrm{cm}^{3}-\mathrm{s}\right)$ is shown. Starting from $Z=4.5 \mathrm{~mm}$ toward the particle stagnation plane $(Z$ near $2.9 \mathrm{~mm})$, following the direction of convection, the volumetric HACA growth rate first increases, peaks near $Z=4.2$ $\mathrm{mm}$ and then decreases. The initial low growth rate near $\mathrm{Z}=4.5 \mathrm{~mm}$ is due to low soot surface area and the concentration of $\mathrm{C}_{2} \mathrm{H}_{2}$, as shown in Fig. $12 \mathrm{~b}$ and Fig. 8c, respectively. As $Z$ decreases, more surface area and higher $\mathrm{C}_{2} \mathrm{H}_{2}$ concentration are available, resulting in the increase in the soot mass growth rate. As $Z$ 
further decrease toward the stagnation plane, however, the soot growth rate reduces to almost zero rapidly near $\mathrm{Z}=3.2 \mathrm{~mm}$, even before reaching the stagnation plane. Note that in the region $3.5<\mathrm{Z}<4.0 \mathrm{~mm}$, the surface area and $\mathrm{C}_{2} \mathrm{H}_{2}$ concentration are both increasing while the soot growth rate is decreasing as $Z$ decreases (Fig. 12c). This seemingly strange trend is actually caused by the decrease in temperature as moving away from the flame zone. Besides $\mathrm{C}_{2} \mathrm{H}_{2}$ concentration and surface area, the HACA growth rate also strongly depends on temperature as it has relatively high activation energy. Near $Z=3.5 \mathrm{~mm}$, the temperature is about $1300 \mathrm{~K}$, which is too low for rapid soot surface growth. This is consistent with previous findings [70] that soot growth region has a lower temperature boundary of $1400 \mathrm{~K}$ for an ethylene SF counterflow flame. Regarding the effect of $V_{0}$, it is clear that the increase in $V_{0}$ appreciably reduces the growth rate. In addition, the time available for soot growth also decreases with $V_{0}$.

The soot surface growth rate per unit surface area could be obtained by dividing the volumetric growth rate by the surface area per unit volume. The result is presented in Fig. 12d. The peak growth rate per unit mass is highest for the flame with the largest $V_{0}$, which has the lowest soot loading. This is in contrary to the results for the volumetric soot growth rate. A closer look at Fig. 8a reveals that although the flames with higher $V_{0}$ has lower maximum flame temperature due to flame weakening, near $Z=4.2 \mathrm{~mm}$ where soot surface growth peaks, the flame with lower $V_{0}$ actually has higher temperature in that region. Since the soot growth rate per unit area has been normalized by surface areas, it mainly depends on $\mathrm{C}_{2} \mathrm{H}_{2}$ concentration and local temperature, while is independent of local soot loading. This explains the increasing trend of the soot growth rate per unit area with increasing $V_{0}$, as well as it peaks at a location where soot loading is very low.

Based on the above the discussion, the reasons for reduced soot loading with increasing $V_{0}$ can be summarized as: (1) reduced PAH concentration /soot inception rate and thus less soot surface area per unit volume; (2) reduced soot surface growth rate per unit volume; (3) reduced residence time (from inception region to particle stagnation plane) available for soot surface reactions to take place. 


\section{Concluding remarks}

Sooting characteristics of counterflow diffusion flames with varying strain rate have been studied experimentally by adopting LII, LE/LS and PAH LIF techniques. The effects of $X_{\mathrm{O}}$ and fuel type in CDFs with various strain rates were also investigated. Numerical simulation with a detailed gas phase reaction mechanism and a newly developed soot model was performed. The results are summarized as follows.

While the well-known fact that increase in strain rate tends to reduce SVF has been confirmed experimentally and explained based on detailed numerical simulation, more important conclusions of the current study include the following:

(1) An increase in $X_{\mathrm{O}}$ increased the soot volume fraction of the $\mathrm{C}_{2} \mathrm{H}_{4} \mathrm{CDFs}$ and decreased its sensitivity to the strain rate. With respect to the effect of fuel type, at a fixed $X_{\mathrm{O}}$, the soot loading followed the order of $\mathrm{C}_{3} \mathrm{H}_{6}>\mathrm{C}_{2} \mathrm{H}_{4}>\mathrm{C}_{3} \mathrm{H}_{8}>\mathrm{C}_{2} \mathrm{H}_{6}$, and the sensitivity of SVF on strain rate became lower for higher sooting fuels.

(2) When the soot loading of flames were matched at a reference strain rate by adjusting $X_{\mathrm{O}}$, their dependence on strain rate became similar. A correlation was observed between peak SVF in the flames and its sensitivity to strain rates, indicating the dominant role of soot loading itself in determining the strain rate sensitivity. These results may find application in predicting strain rate effects on soot formation with only knowledge of soot loading at a reference strain rate. The detailed explanation of this behavior, however, requires extensive study on detailed PAH measurements in the future.

(3) The experimental PAH LIF data and numerical simulation both confirmed larger PAHs were more sensitive to strain rate than smaller ones. PAH concentrations and their dependence on strain rate were fuel dependent, even when the flames of different fuels have the same soot loading at a reference strain rate. The temperature effect is thought to compensate this to have similar soot loading. 
(4) The average soot size and peak soot number density decreased with the increase in strain rates, which can be attributed to the decreases in PAH concentrations and the resulting decrease in soot inception rate along with the decrease in the residence time for soot undergoing surface growth.

\section{Acknowledgements}

This study was supported by Saudi Aramco and KAUST.

\section{References}

[1] H. Wang, Proc. Combust. Inst. 33 (2011) 41-67.

[2] I.M. Kennedy, Proc. Combust. Inst. 31 (2007) 2757-2770.

[3] A. Cuoci, A. Frassoldati, T. Faravelli, E. Ranzi, Proc. Combust. Inst. 32 (2009) 1335-1342.

[4] N. Peters, Proc. Combust. Inst. 21 (1988) 1231-1250.

[5] K.T. Kang, J.Y. Hwang, S.H. Chung, W. Lee, Combust. Flame 109 (1997) 266-281.

[6] A. Beltrame, P. Porshnev, W. Merchan-Merchan, A. Saveliev, A. Fridman, L.A. Kennedy, O. Petrova, S. Zhdanok, F. Amouri, O. Charon, Combust. Flame 124 (2001) 295-310.

[7] H. Wang, D.X. Du, C.J. Sung, C.K. Law, Proc. Combust. Inst. (1996) 2359-2368.

[8] M.E. Decroix, W.L. Roberts, Combust. Sci. Technol. 160 (2000) 165-189.

[9] U. Vandsburger, I.M. Kennedy, I. Glassman, Proc. Combust. Inst. 20 (1985) 1105-1112.

[10] M. Yamamoto, S. Duan, S. Senkan, Combust. Flame 151 (2007) 532-541.

[11] H. Böhm, K. Kohse-Höinghaus, F. Lacas, C. Rolon, N. Darabiha, S. Candel, Combust. Flame 124 (2001) 127-136.

[12] J. Xiao, E. Austin, W.L. Roberts, Combust. Sci. Technol. 177 (2005) 691-713.

[13] V. Huijnen, A.V. Evlampiev, L.M.T. Somers, R.S.G. Baert, L.P.H. de Goey, Combust. Sci. Technol. 182 (2010) 103-123.

[14] D.X. Du, R.L. Axelbaum, C.K. Law, Proc. Combust. Inst. 22 (1989) 387-394.

[15] D.X. Du, R.L. Axelbaum, C.K. Law, Proc. Combust. Inst. 23 (1991) 1501-1507.

[16] D.X. Du, R.L. Axelbaum, C.K. Law, Combust. Flame 102 (1995) 11-20.

[17] F.N. Egolfopoulos, C.S. Campbell, J Fluid Mech 318 (1996) 1-29.

[18] F.N. Egolfopoulos, Int J Energ Res 24 (2000) 989-1010.

[19] H.G. Im, C.K. Law, J.S. Kim, F.A. Williams, Combust. Flame 100 (1995) 21-30.

[20] A. Cuoci, A. Frassoldati, T. Faravelli, E. Ranzi, Combust. Sci. Technol. 180 (2008) 767-784.

[21] A. Cuoci, A. Frassoldati, T. Faravelli, E. Ranzi, Combust. Flame 156 (2009) 2010-2022.

[22] Q. Feng, A. Jalali, A.M. Fincham, Y.L. Wang, T.T. Tsotsis, F.N. Egolfopoulos, Combust. Flame 159 (2012) 1876-1893.

[23] Y. Wang, S.H. Chung, Combust. Flame 161 (2014) 1224-1234.

[24] P.H. Joo, Y. Wang, A. Raj, S.H. Chung, Proc. Combust. Inst. 34 (2013) 1803-1809.

[25] B.C. Choi, S.K. Choi, S.H. Chung, Proc. Combust. Inst. 33 (2011) 609-616.

[26] Y.L. Wang, Q. Feng, F.N. Egolfopoulos, T.T. Tsotsis, Combust. Flame 158 (2011) 1507-1519.

[27] C.S. Ji, E. Dames, Y.L. Wang, H. Wang, F.N. Egolfopoulos, Combust. Flame 157 (2010) 277-287.

[28] K. Seshadri, F.A. Williams, Int J Heat Mass Tran 21 (1978) 251-253. 
[29] B. Axelsson, R. Collin, P.E. Bengtsson, Appl. Optics 39 (2000) 3683-3690.

[30] R.L. VanderWal, Appl. Optics 35 (1996) 6548-6559.

[31] S. De Luliis, F. Cignoli, G. Zizak, Appl. Optics 44 (2005) 7414-7423.

[32] F. Beretta, V. Cincotti, A. Dalessio, P. Menna, Combust. Flame 61 (1985) 211-218.

[33] L. Petarca, F. Marconi, Combust. Flame 78 (1989) 308-325.

[34] I.R. Berman, Handbook of Fluorescence Spectra of Aromatic Molecules, Academic Press, New

York, 1971.

[35] A. Ciajolo, R. Ragucci, B. Apicella, R. Barbella, M. de Joannon, A. Tregrossi, Chemosphere 42 (2001) 835-841.

[36] S.M. Lee, S.S. Yoon, S.H. Chung, Combust. Flame 136 (2004) 493-500.

[37] R.J. Santoro, H.G. Semerjian, R.A. Dobbins, Combust. Flame 51 (1983) 203-218.

[38] A. Eremin, E. Gurentsov, E. Popova, K. Priemchenko, Appl. Phys. B 104 (2011) 285-295.

[39] J. Simonsson, N.-E. Olofsson, S. Török, P.-E. Bengtsson, H. Bladh, Appl. Phys. B 10.1007/s00340015-6079-z (2015) 1-11.

[40] J. Zerbs, K.P. Geigle, O. Lammel, J. Hader, R. Stirn, R. Hadef, W. Meier, Appl. Phys. B 96 (2009) 683-694.

[41] F. Migliorini, K.A. Thomson, G.J. Smallwood, Appl. Phys. B 104 (2011) 273-283.

[42] S. Bejaoui, X. Mercier, P. Desgroux, E. Therssen, Combust. Flame 161 (2014) 2479-2491.

[43] M. Leschowski, K.A. Thomson, D.R. Snelling, C. Schulz, G.J. Smallwood, Appl. Phys. B 10.1007/s00340-015-6092-2 (2015) 1-12.

[44] Y. Wang, A. Raj, S.H. Chung, Combust. Flame 160 (2013) 1667-1676.

[45] Y. Wang, A. Raj, S.H. Chung, Combust. Flame 162 (2015) 586-596.

[46] H. Wang, X. You, A. Joshi, S. Davis, A. Laskin, F.N. Egolfopoulos, C.K. Law, http://ignis.usc.edu/USC_Mech_II.htm (2007).

[47] J. Appel, H. Bockhorn, M. Frenklach, Combust. Flame 121 (2000) 122-136.

[48] J.Y. Hwang, S.H. Chung, Combust. Flame 125 (2001) 752-762.

[49] S.J. Harris, I.M. Kennedy, Combust. Sci. Technol. 59 (1988) 443-454.

[50] M. Frenklach, S.J. Harris, J Colloid Interf Sci 118 (1987) 252-261.

[51] M. Frenklach, Chem Eng Sci 57 (2002) 2229-2239.

[52] Chemkin Pro: a chemical kinetics package for the analysis of gas-phase chemical kinetics, Reaction

Desig, Release 15112, 2011.

[53] L.A. Melton, Appl. Optics 23 (1984) 2201-2208.

[54] J.Y. Hwang, W. Lee, H.G. Kang, S.H. Chung, Combust. Flame 114 (1998) 370-380.

[55] T. Poinsot, D. Veynante, Theoretical and numerical combustion, Edwards, Philadelphia, 2005, p.^pp.

[56] C.K. Law, Proc. Combust. Inst. 22 (1989) 1381-1402.

[57] I. Glassman, Proc. Combust. Inst. 22 (1989) 295-311.

[58] N. Ladommatos, P. Rubenstein, P. Bennett, Fuel 75 (1996) 114-124.

[59] H.F. Calcote, D.M. Manos, Combust. Flame 49 (1983) 289-304.

[60] L.M. Li, P.B. Sunderland, Combust. Sci. Technol. 184 (2012) 829-841.

[61] F. Qi, Proc. Combust. Inst. 34 (2013) 33-63.

[62] N. Hansen, T.A. Cool, P.R. Westmoreland, K. Kohse-Höinghaus, Prog. Energy Combust. Sci. 35 (2009) 168-191.

[63] A. Gomez, D.E. Rosner, Combust. Sci. Technol. 89 (1993) 335-362.

[64] S.B. Dworkin, Q.A. Zhang, M.J. Thomson, N.A. Slavinskaya, U. Riedel, Combust. Flame 158 (2011) 1682-1695.

[65] M. Frenklach, H. Wang, Proc. Combust. Inst. 23 (1991) 1559-1566.

[66] H.F. Jin, Y.Z. Wang, K.W. Zhang, H.S. Guo, F. Qi, Proc. Combust. Inst. 34 (2013) 779-786.

[67] Z.D. Wang, Y.Y. Li, F. Zhang, L.D. Zhang, W.H. Yuan, Y.Z. Wang, F. Qi, Proc. Combust. Inst. 34 (2013) 1785-1793. 
[68] S.A. Skeen, B. Yang, H.A. Michelsen, J.A. Miller, A. Violi, N. Hansen, Proc. Combust. Inst. 34 (2013) 1067-1075.

[69] B.C. Choi, S.K. Choi, S.H. Chung, J.S. Kim, J.H. Choi, Int. J. Auto. Tech. 12 (2011) 183-191.

[70] S.S. Yoon, S.M. Lee, S.H. Chung, Proc. Combust. Inst. 30 (2005) 1417-1424. 


\section{Figure captions}

Fig.1 Effect of $V_{0}$ on peak SVF for $\mathrm{C}_{2} \mathrm{H}_{4} \mathrm{CDF}$ with varying $X_{\mathrm{O}}$

Fig.2 Effect of $V_{0}$ on peak SVF for CDF of different fuels

Fig.3 Dependence of peak SVF for CDFs of different fuels on $V_{0}$

Fig.4. Correlation between soot loading at its sensitivity to strain rate

Fig.5. Dependence of peak PAH LIF signals on $V_{0}$ for $\mathrm{C}_{3} \mathrm{H}_{8}$ flames with different $X_{\mathrm{O}}$

Fig.6. Dependence of peak PAH concentration for CDFs of different fuels on $V_{0}$

Fig.7 Comparison between the effect of $V_{0}$ on the experimental LIF signals and that on computed concentration of PAH

Fig.8 Simulated flame structures at different $V_{0}$

Fig.9 Experimental and simulated soot volume fractions for ethylene CDFs at various $V_{0}$

Fig.10 Experimental and simulated average soot diameters for ethylene CDFs at various $V_{0}$

Fig.11 Experimental and simulated average soot number density for ethylene CDFs at various $V_{0}$

Fig.12 Computed soot growth process for ethylene CDFs at various $V_{0}$, (a) particle nucleation rates; (b) soot particle surface areas; (c) volumetric HACA soot mass growth rates; (d) HACA soot mass growth rates per unit area 

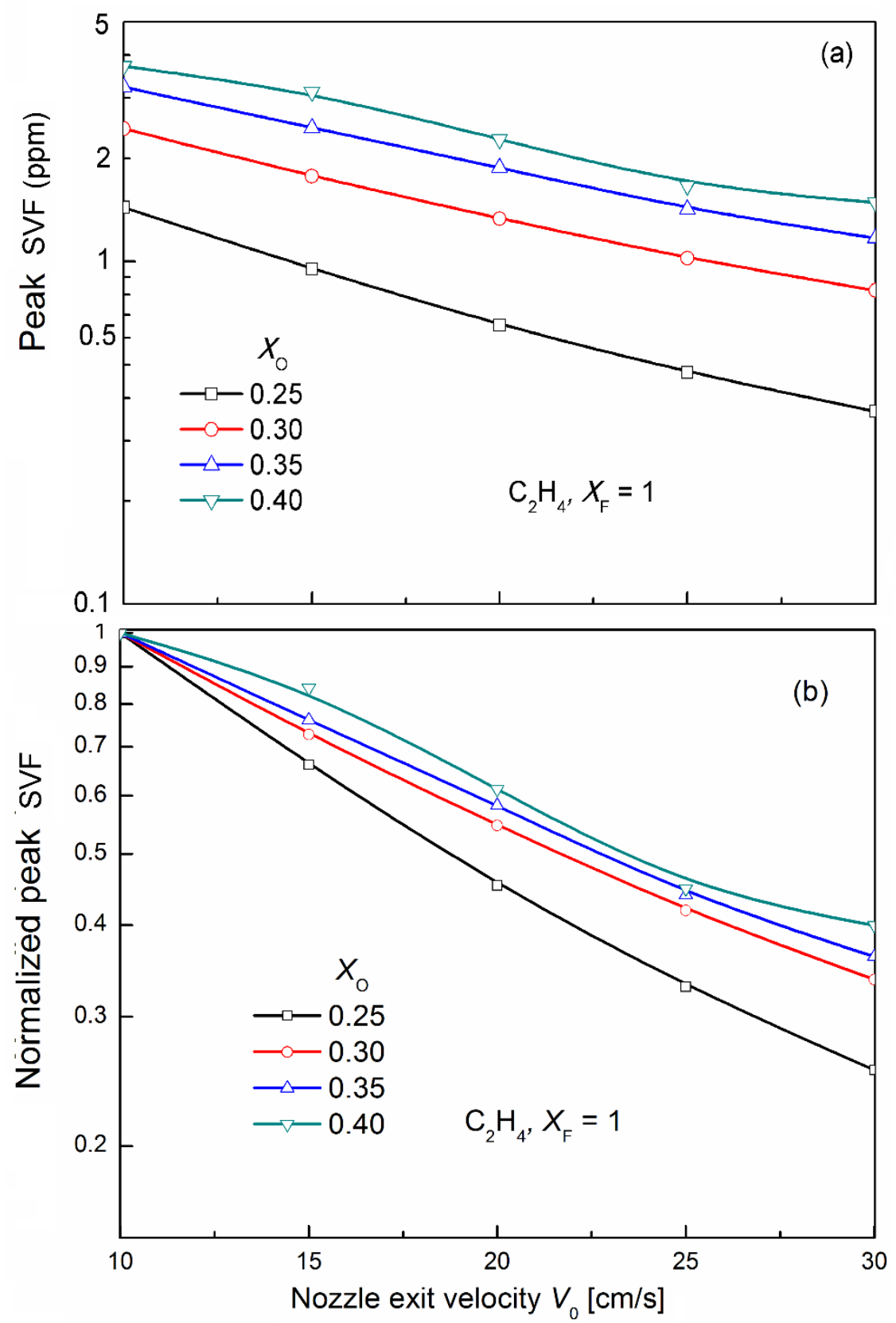

Fig.1 Effect of $V_{0}$ on peak SVF for $\mathrm{C}_{2} \mathrm{H}_{4} \mathrm{CDF}$ with varying $X_{\mathrm{O}}$ 

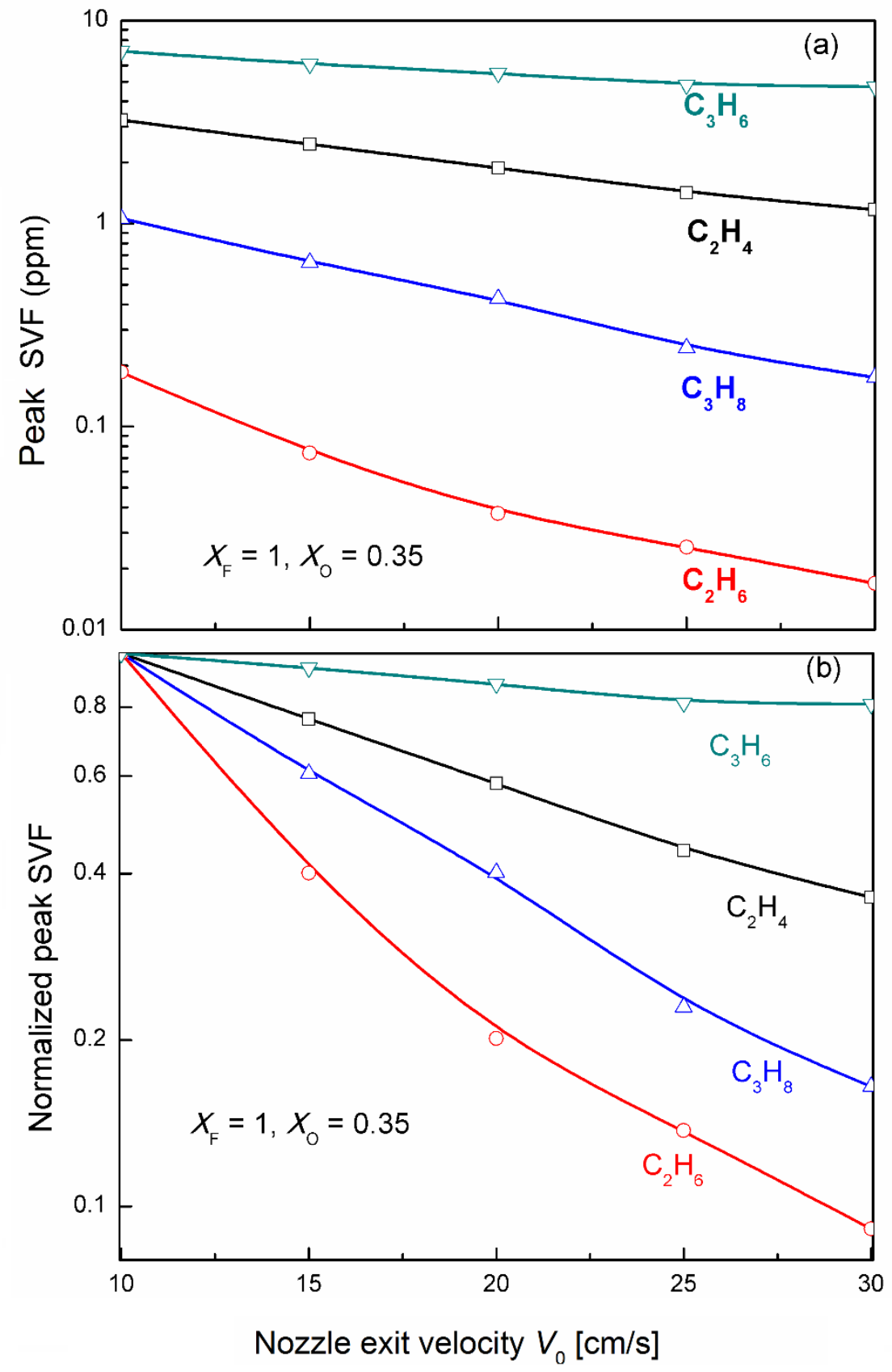

Fig.2 Effect of $V_{0}$ on peak SVF for CDF of different fuels 


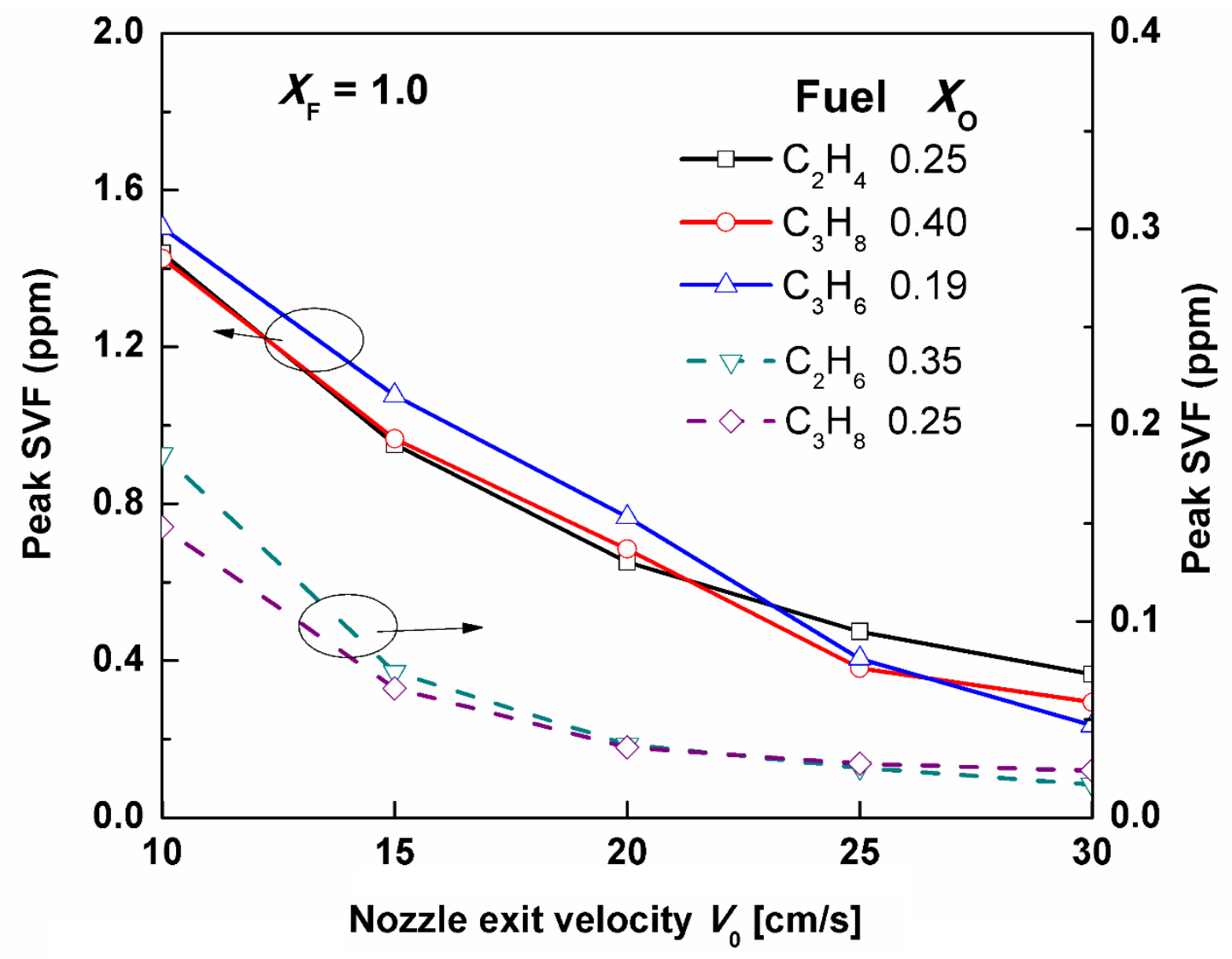

Fig.3 Dependence of peak SVF for CDFs of different fuels on $V_{0}$ 


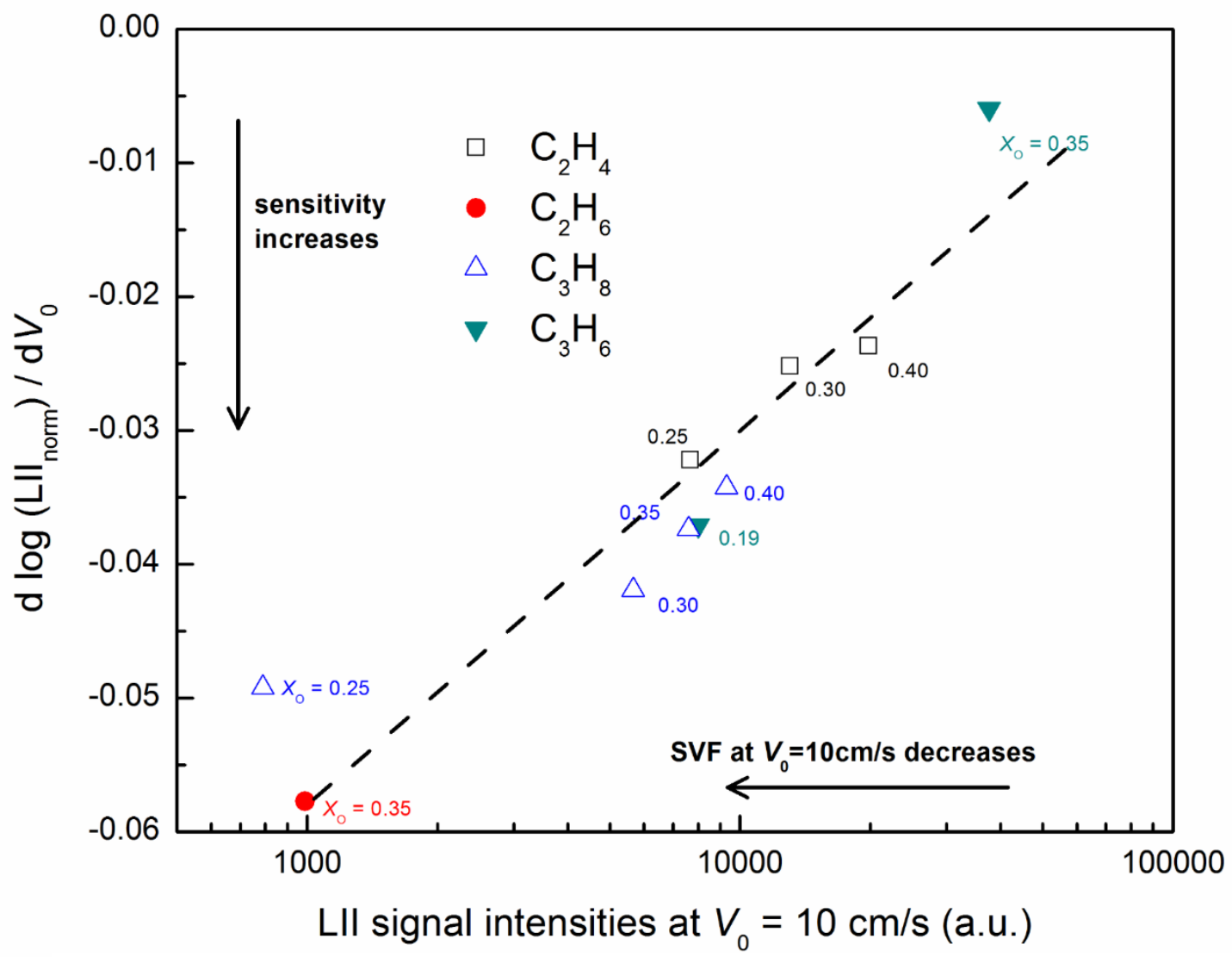

Fig.4 Correlation between soot loading at its sensitivity to strain rate 


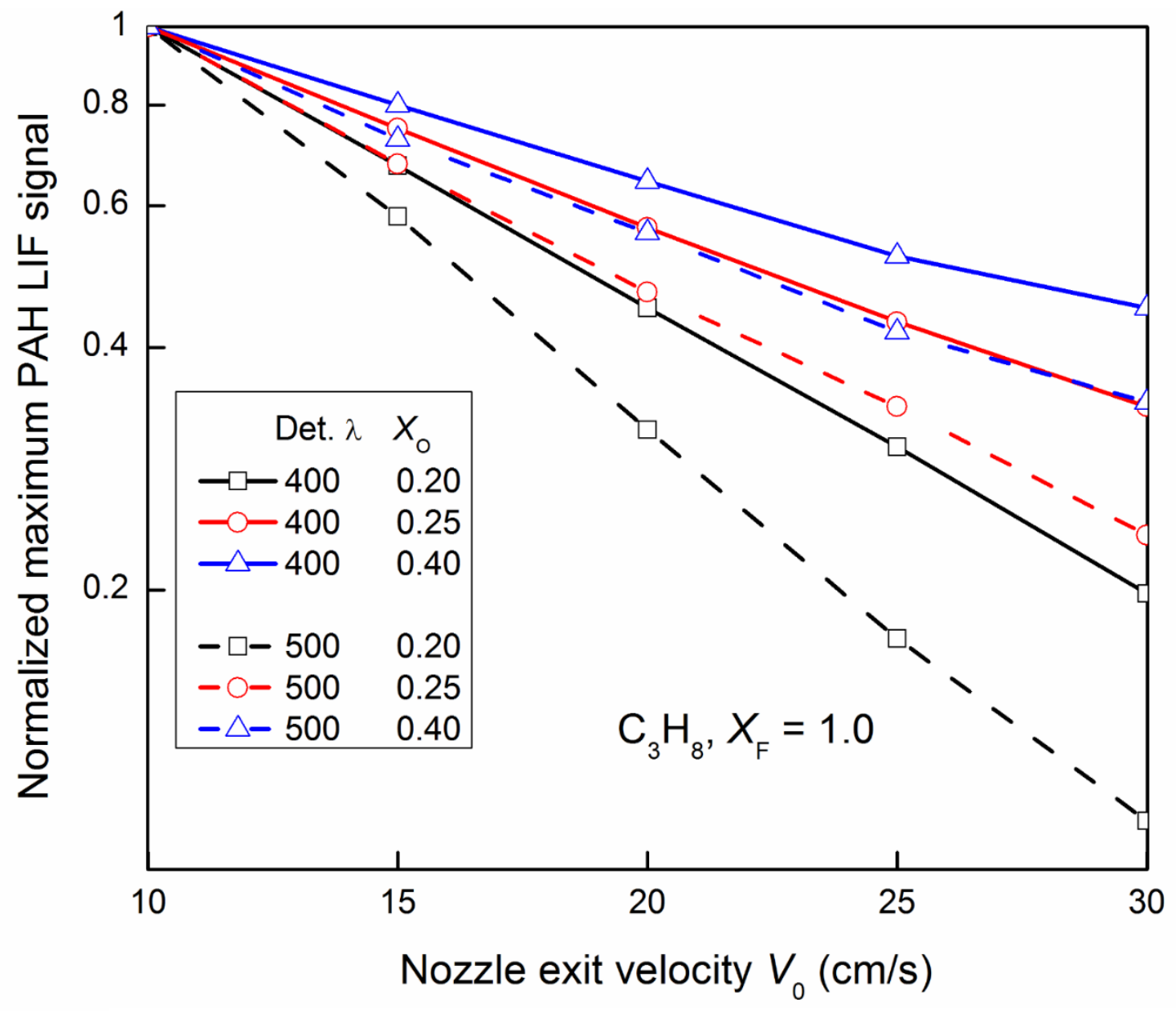

Fig.5 Dependence of peak PAH LIF signals on $V_{0}$ for $\mathrm{C}_{3} \mathrm{H}_{8}$ flames with different $X_{\mathrm{O}}$ 

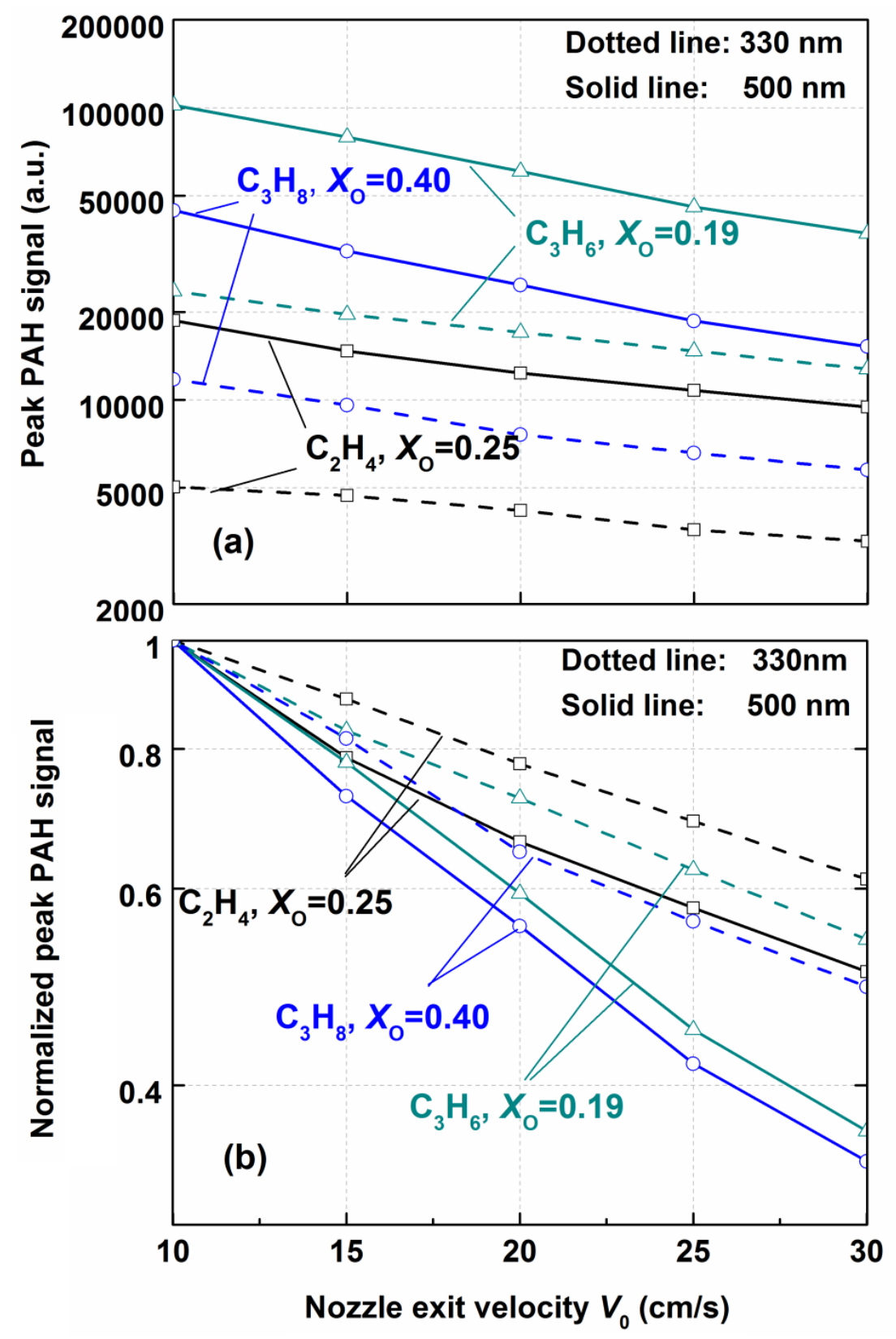

Fig.6 Dependence of peak PAH concentration for CDFs of different fuels on $V_{0}$ 


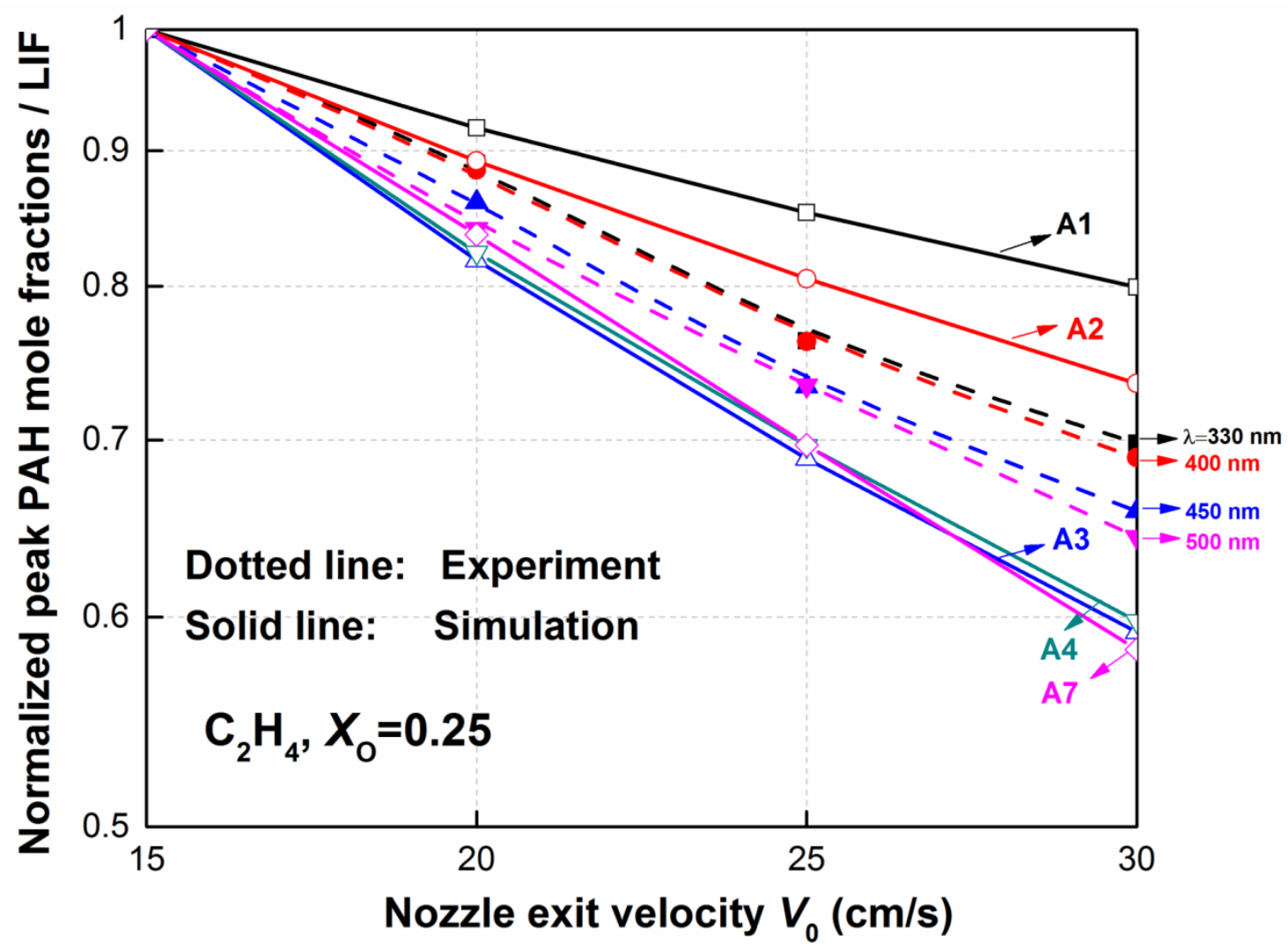

Fig.7 Comparison between the effect of $V_{0}$ on the experimental LIF signals and that on computed concentration of PAH 

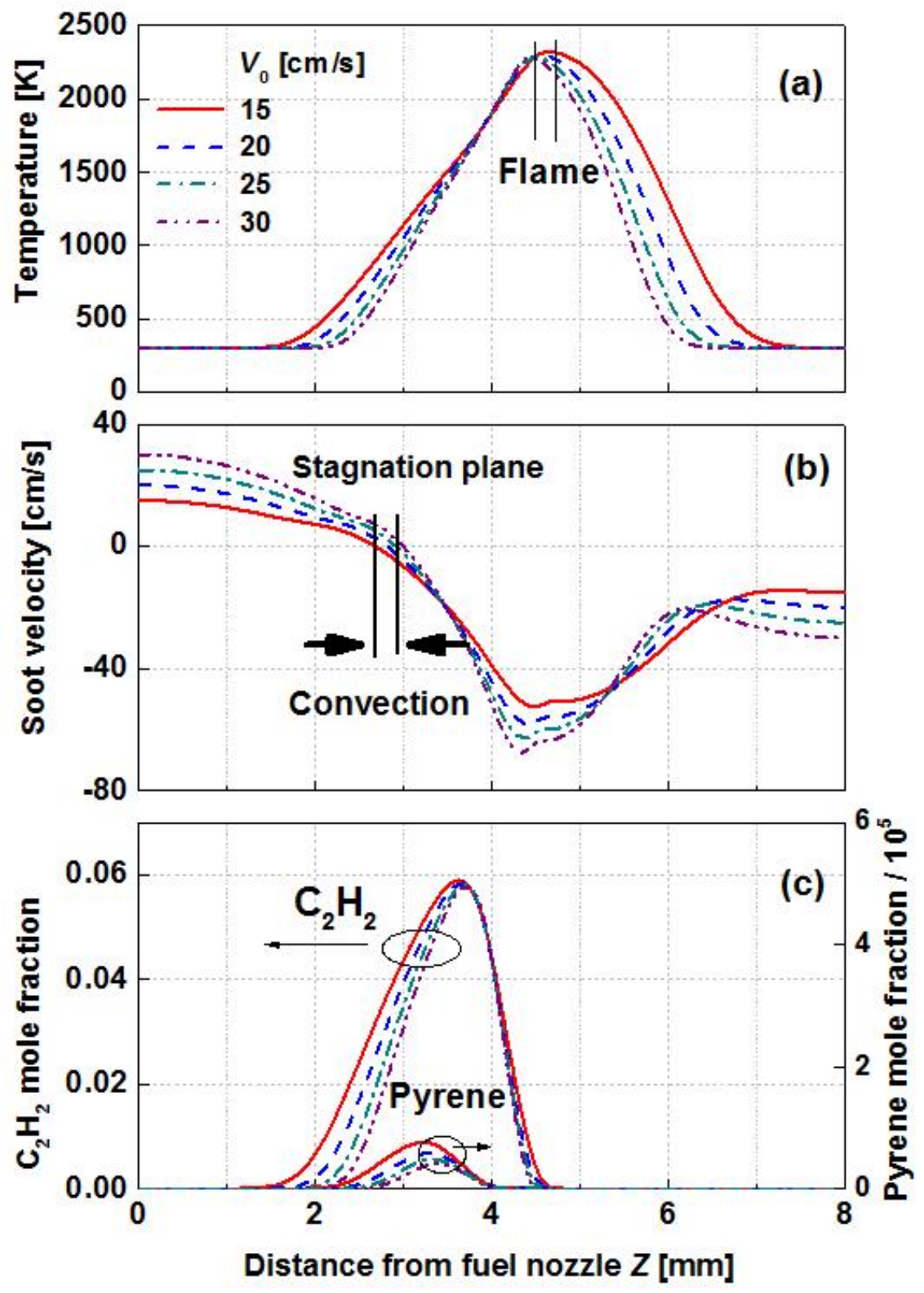

Fig.8 Simulated flame structures at different $V_{0}$ 

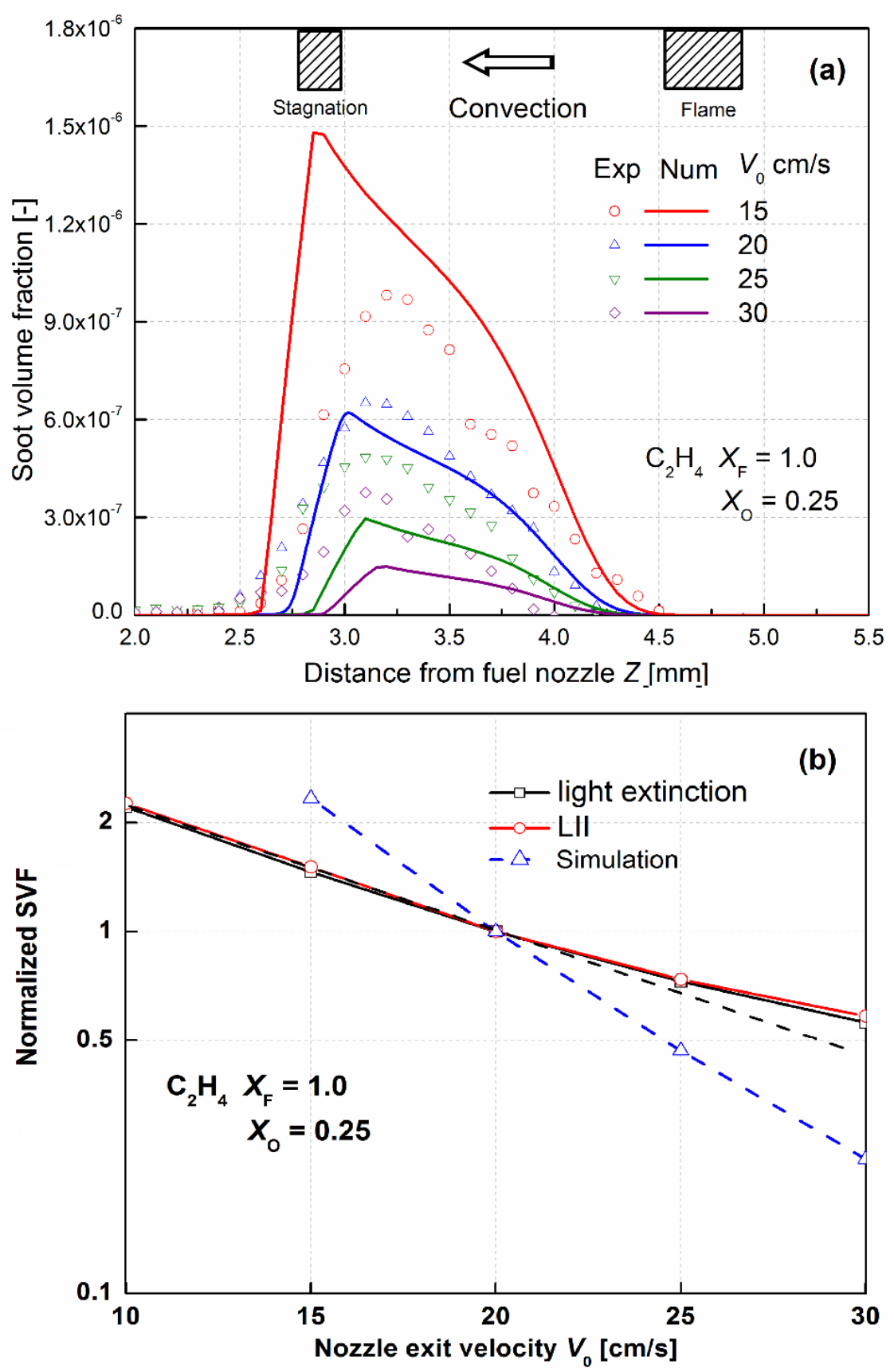

Fig.9 Experimental and simulated soot volume fractions for ethylene CDFs at various $V_{0}$ 


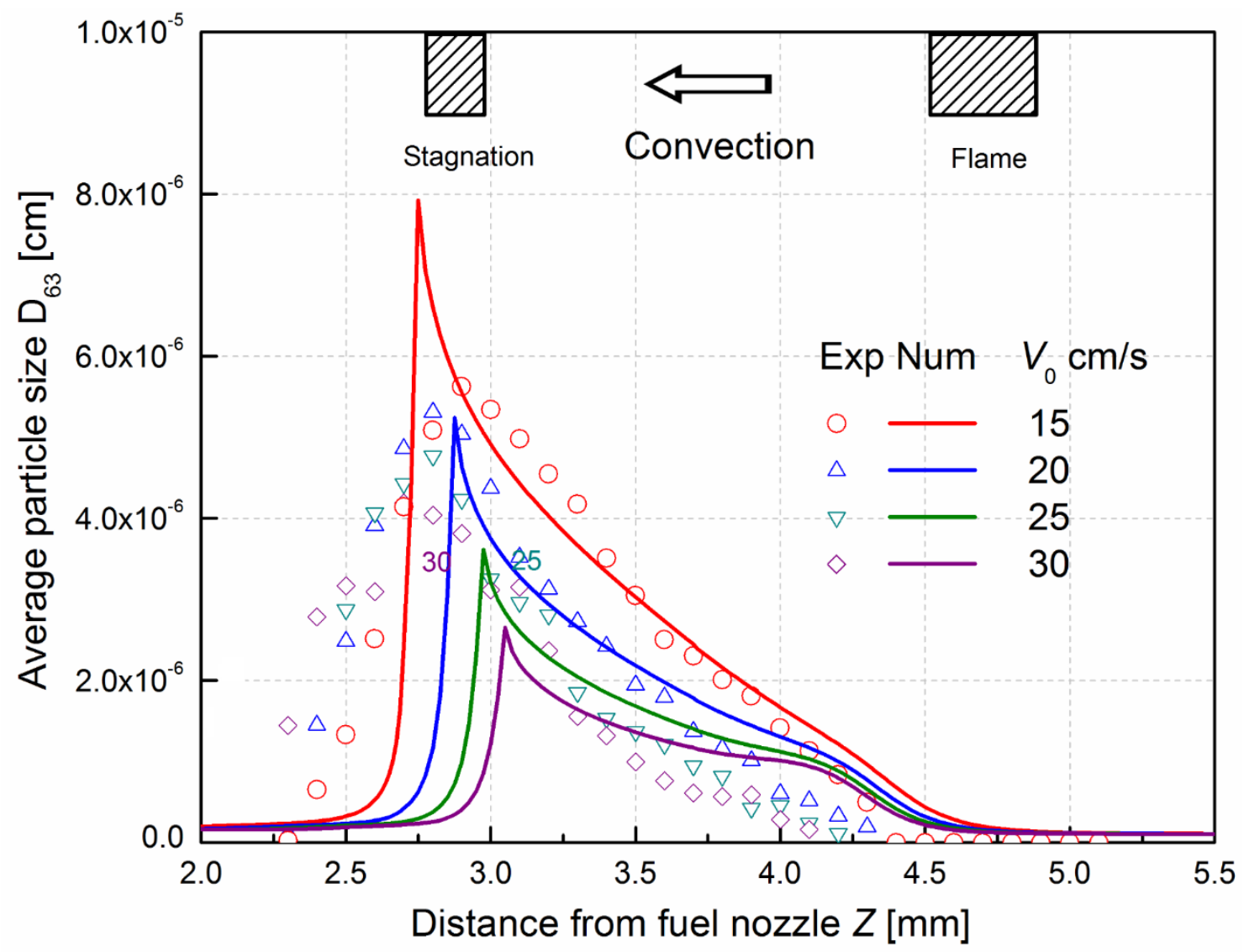

Fig.10 Experimental and simulated average soot diameters for ethylene CDFs at various $V_{0}$ 


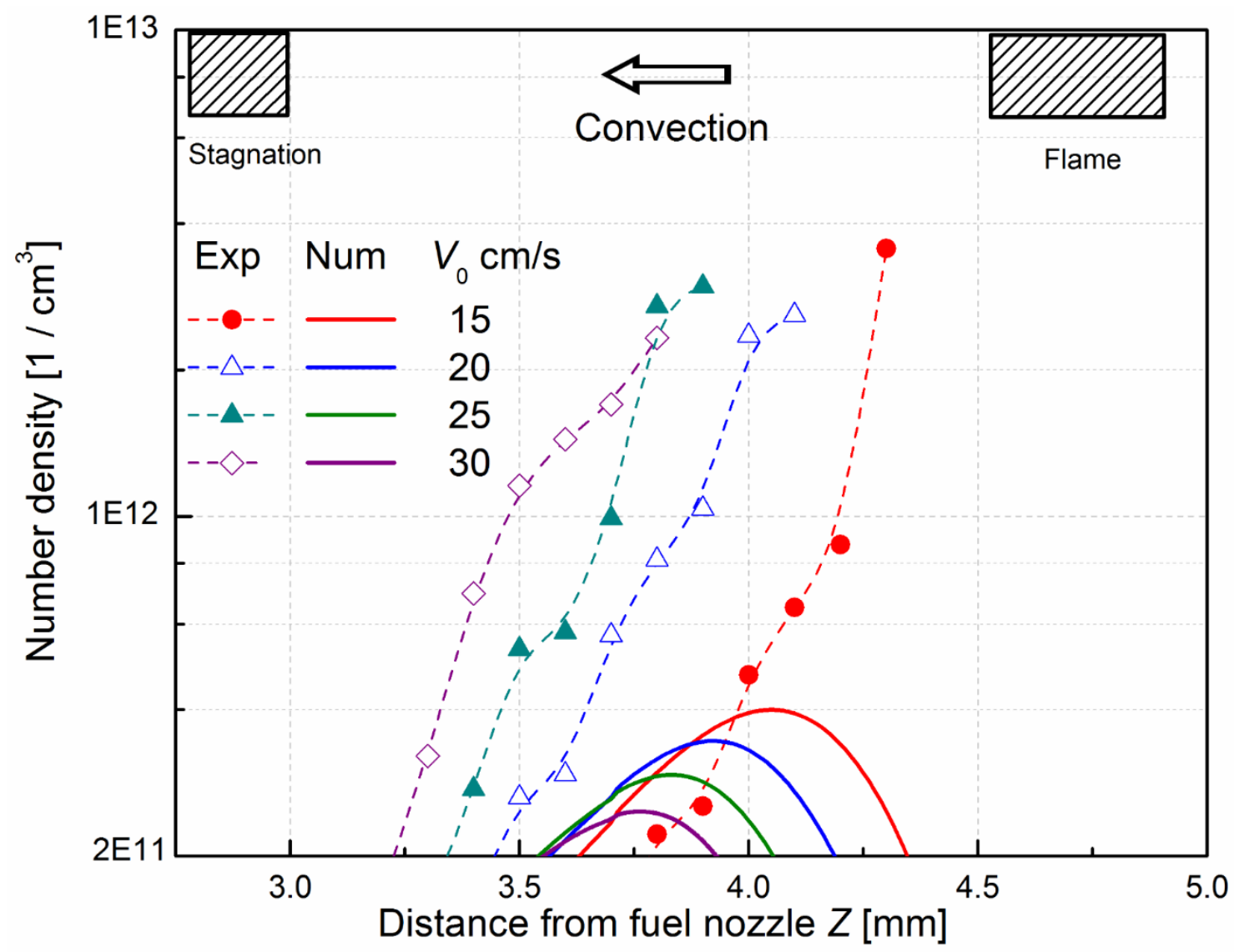

Fig.11 Experimental and simulated average soot number density for ethylene CDFs at various $V_{0}$ 

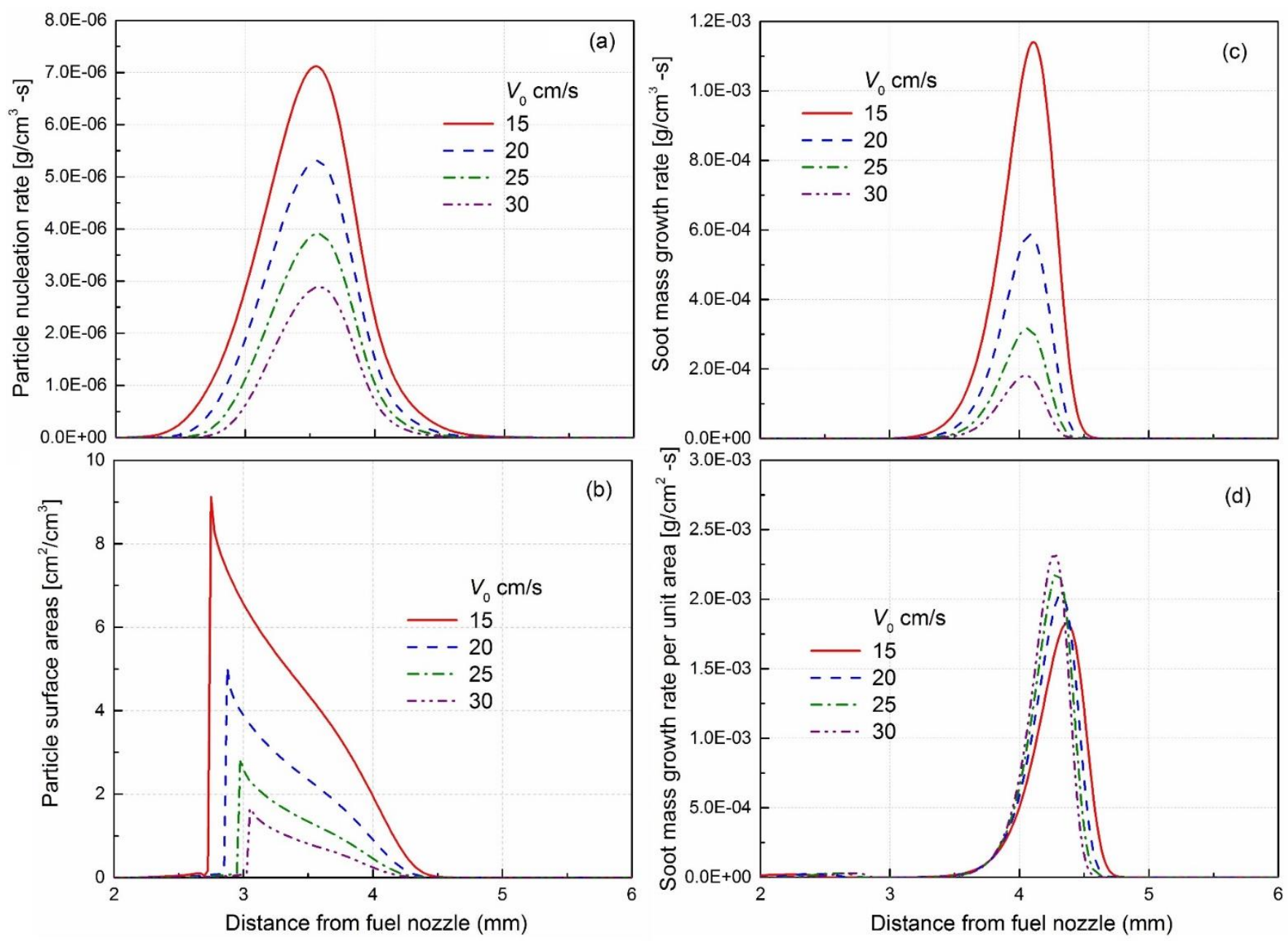

Fig. 12 Computed soot growth process for ethylene CDFs at various $V_{0}$, (a) particle nucleation rates; (b) soot particle surface areas; (c) volumetric HACA soot mass growth rates; (d) HACA soot mass growth rates per unit area 